\title{
PHASE EQUILIBRIA OF TRIOLEIN TO BIODIESEL REACTOR SYSTEMS
}

\section{Cory Silva $^{1}$, Lindsay Soh ${ }^{2}$, Antonio Barberio ${ }^{1}$, Julie Zimmerman ${ }^{3}$, and Warren D. Seider ${ }^{{ }^{*}}$}

1. Department of Chemical and Biomolecular Engineering, University of Pennsylvania, Philadelphia, PA 19104-6393

2. Department of Chemical and Biomolecular Engineering Lafayette University, Easton, PA 18042

3. Department of Chemical and Environmental Engineering Yale University, New Haven, CT 06511

*_C Corresponding author for this work: seider@seas.upenn.edu 372Towne Building, Philadelphia, PA 19104-6393

\begin{abstract}
The phase equilibria of biodiesel systems, which are comprised of mixtures of triolein, methanol, carbon dioxide, methyl-oleate, glycerol, and water, are analyzed using PC-SAFT in ASPEN PLUS and SAFT- $\gamma$ Mie in gPROMS (gSAFT) for systems in the vicinity of their critical point. Pure-species density and liquid vapor-pressure data were used to regress pure-species parameters for both variants of the SAFT equations. Binary vapor-liquid and liquid-liquid equilibrium data for the six species were used to obtain binary interaction parameters in PCSAFT and cross parameters in SAFT- $\gamma$ Mie. Vapor-liquid and liquid-liquid equilibria data from the literature were supplemented with experimental data taken herein to obtain a complete set of binary parameters. Overall, SAFT- $\gamma$ Mie gave the best agreement with binary data, but had difficulty predicting liquid-liquid behavior in ternary systems. PC-SAFT showed good agreement with experimental data, especially for LLE systems. However, the Gibbs flash method in ASPEN PLUS yielded poor predictions for the triolein, methanol, and carbon dioxide mixture in the VLE and VLLE regions - but, addition of a tangent-plane-distance code revealed the prediction of unstable phases. Similarly, gSAFT in gPROMS, was unable to predict correct phase distributions, using parameters regressed in prior studies. Consequently, to examine the conversion of triolein to methyl-oleate observed experimentally at VLLE conditions $\left(95^{\circ} \mathrm{C} 9.65\right.$ $\mathrm{MPa}$ ), RK-ASPEN (without binary interaction parameters) was used in a custom-written FORTRAN reactor program.
\end{abstract}

Keywords: SAFT, GXL, supercritical, $\mathrm{CO}_{2}$ 


\section{Introduction}

Biodiesel offers a renewable, carbon-neutral alternative to its fossil fuel counterpart. However, with plummeting oil prices, alternative fuels have become less competitive, and thus, improved processes are needed to reduce costs. In a previous study, which examined algae-tobiodiesel ventures, the extraction step was found to be energy intensive and have widely variable economic estimates [1]. An alternative, using high-pressure $\mathrm{CO}_{2}$, has been demonstrated experimentally [2] and found to highly-effective and also selective at extracting algae-oil. Similarly, several studies have shown the potential of supercritical $\mathrm{CO}_{2}$ as a co-solvent in the transesterification reactions [3-5], allowing high conversions at relatively low temperatures. It is thus possible that these two steps could be combined, although this has not been demonstrated yet. However, performing the oil-extraction and conversion in the same step or at least the same process should yield considerable cost savings by eliminating pre-processing and purification steps that are currently required [1].

This paper focuses on the conversion of triglyceride to biodiesel using supercritical $\mathrm{CO}_{2}$ - with the kinetic mechanism shown in Figure 1, rather than the extraction of oil from algae. Given that the objective is to use algae-derived oils, water is assumed to be present. Due to lack of data, diglycerides and monoglycerides are excluded from the calculations herein. Further, triolein and methyl-oleate were used as exemplars of algal oil and biodiesel for this study as they are the only triglyceride and fatty acid methyl ester (FAME) molecules having sufficient data to be included. As such, this analysis involves just six chemical species: triolein, methyl-oleate, methanol, glycerol, water, and carbon dioxide. In future studies, the number of triglycerides will be increased to accurately represent algae-oils, allowing the extraction step to be modeled.

Kinetic pre-exponential factors and activation energies for the conversion of algae-oils to biofuels are available [5-7]. However, previous studies that modeled the phase behavior for transesterification reactions used crude models (like Redlich-Kwong in ASPEN PLUS [3, 4, 8], which are not suitable in the critical region or with large, asymmetric molecules. The most advanced equations-of-state (EoS) used for supercritical systems have been the Cubic Plus Association (CPA) EoS, which was used to study supercritical alcohols [9-15], and the softSAFT, which was used to study binary systems of $\mathrm{CO}_{2}$ and water, and $\mathrm{CO}_{2}$ and FAME [16].

The objective of this transesterification study is to use the SAFT EoSs to model the phase behavior of a biodiesel reactor [up to three phases (vapor, polar liquid, nonpolar liquid) or as few 
as one supercritical phase [17]]. The miscibility between the phases has drastic effects on the concentrations (and reaction rates). It will be shown that a reliable phase equilibria model is needed to describe the reactor conversions; however, predictions with commercially-available SAFT phase-equilibria models are not yet sufficiently reliable in the critical region for triolein, methanol and $\mathrm{CO}_{2}$. This paper presents experimental data and shows the reason for the inadequacy of their predictions, along with suggestions to improve their predictive capability in future work.

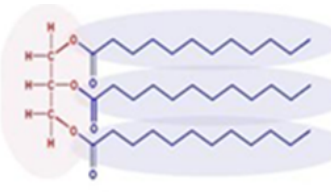

TG

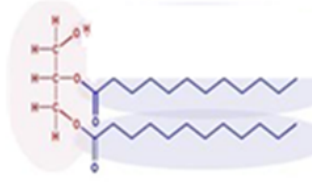

DG

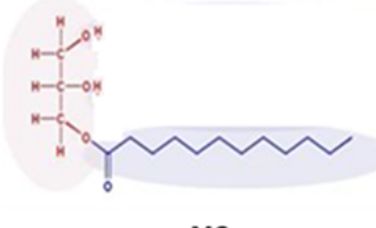

MG
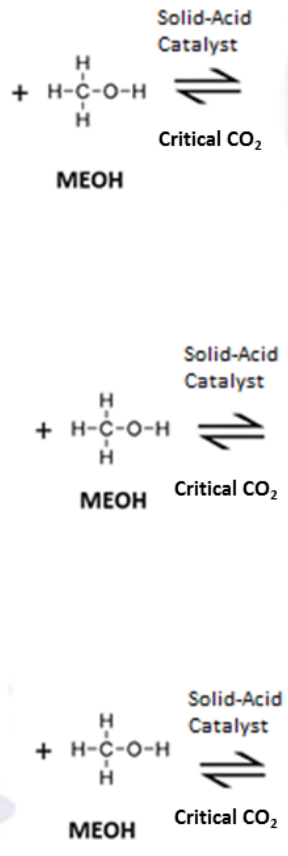

MEOH

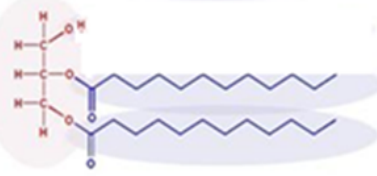

DG

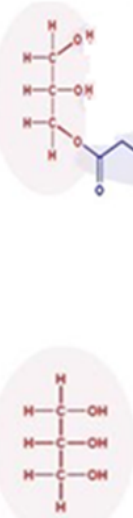

GLY

MG

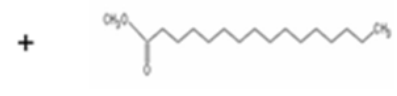

FAME
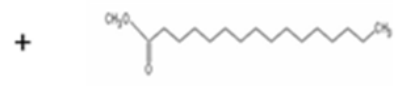

FAME

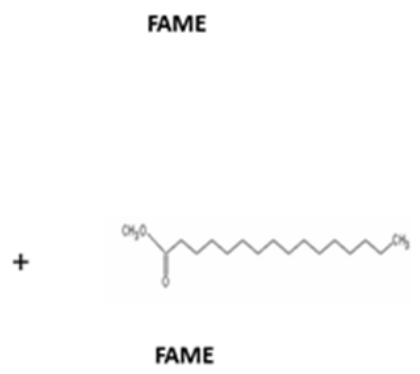

Figure 1. Triolein to biodiesel conversion mechanism. TG is triglyceride (triolein), $\mathrm{MEOH}$ is methanol, DG is diglyceride, FAME is fatty-acid methyl-ester (biodiesel), MG is monoglyceride, GLY is glycerol, and critical $\mathrm{CO}_{2}$ is carbon dioxide in or near the critical region.

In the sections that follow, cubic and SAFT equations-of-state are reviewed, the latter designed for use with long-chain hydrocarbons. Experimental methods are presented, which were used to generate data herein for binary systems, where data were unavailable or unreliable. Most of these data were for liquid-liquid systems, although one vapor-liquid system was studied 
experimentally. Then, pure-species, binary, and ternary data are used to compare two SAFT variants [PC-SAFT in ASPEN PLUS [18, 19] and SAFT- $\gamma$ Mie in gPROMS (gSAFT ${ }^{1}$ ) [20, 21]] and RK-ASPEN. Finally, a multiphase-reactor model, using approximate RK-ASPEN to model VLLE, is formulated and evaluated with experimental data.

\section{Theory}

\subsection{Cubic Equations-of-State}

Cubic equations-of-state (EoS) were first developed roughly 130 years ago and have become the industry standard since the development of computer-aided process design in the 1970s. The cubic EoSs are named as such because they contain a cubed molar volume term (Eq. 1). Numerous variants exist, the most popular of which are the van der Waals equation, SoaveRedlich-Kwong [22], and Peng-Robinson [23]. Herein, a variant of Soave-Redlich-Kwong (RKASPEN) will be used for comparative purposes with the SAFT EoSs. The equations that describe RK-ASPEN are shown below.

$$
\begin{gathered}
P=\frac{R T}{V-b}-\frac{a}{V(V+b)} \\
a=\sum_{i} \sum_{j} x_{i} x_{j}\left(a_{i} a_{j}\right)^{0.5}\left(1-K_{a, i j}\right) \\
b=\sum_{i} \sum_{j} x_{i} x_{j}\left(\frac{b_{i}+b_{j}}{2}\right)\left(1-K_{b, i j}\right)
\end{gathered}
$$

where $R$ is the gas constant $(8.314 \mathrm{~J} / \mathrm{mol}-\mathrm{K}), T$ is temperature, $V$ is the molar volume, $P$ is the pressure, $K_{a, i j}$ and $K_{b, i j}$ are binary interaction parameters, and $a_{i}$ and $b_{i}$ are empirical parameters, calculated using Eq. 4-7. The attractive parameter, $a_{i}$, depends on the reduced temperature $\left(T_{r i}=\right.$ $\left.T / T_{c i}\right)$, the critical temperature $\left(T_{c i}\right)$ and critical pressure $\left(P_{c i}\right)$, the accentric factor $\left(\omega_{i}\right)$, and an extra polar parameter $\left(\eta_{i}\right)$. The size parameter, $b_{i}$, depends only on the critical temperature and critical pressure. $\gamma_{i}$ is a parameter that accounts for accentricity of the molecule.

$$
\begin{gathered}
a_{i}=0.42747 \propto_{i} \frac{R^{2} T_{C i}^{2}}{P_{C i}} \\
\propto_{i}=\left[1+\gamma_{i}\left(1-T_{r i}^{0.5}\right)-\eta_{i}\left(1-T_{r i}\right)\left(0.7-T_{r i}\right)\right]^{2} \\
\gamma_{i}=0.48508+1.5517 \omega_{i}-0.15613 \omega_{i}^{2} \\
b_{i}=0.08664 \frac{R T_{C i}}{P_{C i}}
\end{gathered}
$$

\footnotetext{
${ }^{1}$ Note that the equation-of-state is known as SAFT- $\gamma$ Mie. gSAFT is the thermodynamics package developed by Process System Enterprise, which contains the SAFT- $\gamma$ Mie equation-of-state. Note that these two terms are used interchangeably throughout this paper.
} 
The binary interaction parameters, $K_{a, i j}$ and $K_{b, i j}$, are determined from Eq. 8 and 9, in which $K_{a, i j}{ }^{0}$, $K_{a, i j}{ }^{1}, K_{b, i j}{ }^{0}$, and $K_{b, i j}{ }^{1}$ are all parameters regressed using binary vapor-liquid equilibrium (VLE) or liquid-liquid equilibrium (LLE) data [24].

$$
\begin{aligned}
& K_{a, i j}=K_{a, i j}^{0}+K_{a, i j}^{1} \frac{T}{1000} \\
& K_{b, i j}=K_{b, i j}^{0}+K_{b, i j}^{1} \frac{T}{1000}
\end{aligned}
$$

\subsection{PC-SAFT}

More recently, new EoSs were derived using statistical mechanics to represent complex fluid mixtures. The statistical associating fluid theory (SAFT), which treats molecules as freelyjointed spherical segments [25], is prominent among them. Gross and Sadowski modified the original SAFT formulation by: (1) adding a dispersion expression for chain molecules based on perturbation theory [26-29], (2) readjusting the other pure-species parameters to improve accuracy [18], and (3) adding an association term [19]. Their EoS is referred to as the perturbed chain-SAFT, or PC-SAFT.

In PC-SAFT, molecules are modeled as chains of spherical segments. The pair-potential of a segment is described by Eq. 10, which uses a modified square-well potential, in which $u_{i j}(r)$ is the pair-potential, $r$ is the radial distance between segments, $\sigma_{i j}$ is the segment diameter, $\varepsilon_{i j}$ is the energy of the square-well interaction, and $\lambda_{i j}$ is the attractive range of the interaction [18]. In this case, $S_{i j}=0.12 \sigma_{i j}$. Note that the variable, $\lambda_{i j}$, is not actually used in the final version of the equation since it is regressed out, but is included here for completeness.

$$
u_{i j}(r)=\left\{\begin{array}{lc}
\infty, & r<\left(\sigma_{i j}-S_{i j}\right) \\
3 \varepsilon_{i j}, & \left(\sigma_{i j}-S_{i j}\right) \leq r<\sigma_{i j} \\
-\varepsilon_{i j}, & \sigma_{i j}<r \leq \lambda_{i j} \sigma_{i j} \\
0, & r>\lambda_{i j} \sigma_{i j}
\end{array}\right.
$$

The EoS is formulated in terms of the Helmholtz free energy, as shown in Eq. 11. Four terms account for four phenomena: an ideal-gas contribution (ig); a hard-chain contribution (hc), which accounts for repulsive forces between chains (individual species in this work); a 
dispersion (disp) contribution, which accounts for attractive forces between species; and an association contribution (assoc) for species that can hydrogen bond or those with electron lone pairs. For Eq. 11, $A$ is the Helmholtz free energy, $N$ is the number of molecules, $k_{\mathrm{B}}$ is the Boltzmann constant, and $T$ is the absolute temperature.

$$
\frac{A}{N k_{\mathrm{B}} T}=\frac{A^{\mathrm{ig}}}{N k_{\mathrm{B}} T}+\frac{A^{\mathrm{hc}}}{N k_{\mathrm{B}} T}+\frac{A^{\mathrm{disp}}}{N k_{\mathrm{B}} T}+\frac{A^{\text {assoc }}}{N k_{\mathrm{B}} T}
$$

For non-associating molecules, the equation is described by three pure-species parameters: the segment diameter, $\sigma_{i j}$, the energy of the square-well potential $\varepsilon_{i j}$, and the number of segments per chain, $m_{i}$. The like $\left(\varepsilon_{i i}, \sigma_{i i}\right.$, and $\left.m_{i}\right)$ parameters are regressed from pure-species densities and liquid vapor pressures. The unlike parameters $\left(\varepsilon_{i j}\right.$ and $\left.\sigma_{i j}\right)$ are calculated using:

$$
\begin{aligned}
\varepsilon_{i j} & =\sqrt{\varepsilon_{i i} \varepsilon_{j j}}\left(1-K_{i j}\right) \\
\sigma_{i j} & =\frac{1}{2}\left(\sigma_{i i}+\sigma_{j j}\right)
\end{aligned}
$$

where $K_{i j}$ represents the binary interaction parameter for molecules $i$ and $j$, which is regressed using experimental binary data and calculated using Eq. 14. Note that these parameters are $\operatorname{symmetric~}\left(K_{i j}=K_{j i}\right)[24]$.

$$
K_{i j}=K_{i j}^{(1)}+K_{i j}^{(2)} T+\frac{K_{i j}^{(3)}}{T}
$$

The hard-chain contribution is dependent on reduced densities:

$$
\zeta_{n}=\frac{\pi}{6} \rho \sum_{i} x_{i} m_{i} D_{i i}{ }^{n} \quad n \in(0,1,2,3)
$$

where $\zeta_{n}$ is the reduced density, $\rho$ is the number density (molecules $/ \mathrm{m}^{3}$ ), $x_{i}$ is the mole fraction of chemical species $i, m_{i}$ is the number of segments in species $i$, and $D_{i i}$ is a temperature-dependent collision diameter of $i$ (in meters), which is defined in Eq. 16. Note that for a value of $n=3, \zeta_{3}$ is a dimensionless density, more commonly referred to as the packing fraction.

$$
D_{i i}=\int_{0}^{\sigma_{i i}}\left[1-\exp \left(-\frac{u_{i i}(r)}{k_{B} T}\right)\right] d r \quad n \in(0,1,2,3)
$$

The dispersion contribution is characterized as the sum of the first and second order Helmholtz perturbation expansions:

$$
\frac{A^{d i s p}}{N k_{B} T}=\frac{A_{1}}{N k_{B} T}+\frac{A_{2}}{N k_{B} T}
$$

where the first and second order Helmholtz functions depend on the interacting segments' radial distributions, hard-chain Helmholtz energies, reduced radial distance, and reduced potential function [18]. The universal model constants (not described in this paper) used to calculate the 
two Helmholtz terms were adjusted using pure-species data from the n-alkane series. These adjustments eliminate the parameter, $\lambda_{i j}$. For further discussion of this topic, see the original PCSAFT paper [18].

Finally, the association term is:

$$
\frac{A^{a s s c}}{N k_{B} T}=\sum_{i} x_{i}\left[\sum_{A}\left[\operatorname{Ln}\left(X_{A_{i}}\right)-\frac{X_{A_{i}}}{2}\right]+\frac{1}{2} M_{i}\right]
$$

where $M_{i}$ is the number of association sites on each molecule and $X_{A i}$ is the mole fraction of molecules $i$ not bonded at an individual site, $A$. The summation is performed over all associating sites for each molecule. $X^{A i}$ is dependent on a bonding volume term, $\kappa^{A i B j A}$, and a dimensionless association energy term, $\varepsilon^{A i B j} / k_{B} T$, which are the other pure-species parameters required for an associating molecule. For cross-associating mixtures, these terms are described by simple combining rules:

$$
\begin{gathered}
\varepsilon^{\mathrm{A}_{i} \mathrm{~B}_{j}}=\frac{1}{2}\left(\varepsilon^{\mathrm{A}_{i} \mathrm{~B}_{i}}+\varepsilon^{\mathrm{A}_{j} \mathrm{~B}_{j}}\right) \\
\kappa^{\mathrm{A}_{i} \mathrm{~B}_{j} \mathrm{~A}}=\sqrt{\kappa^{\mathrm{A}_{i} \mathrm{~B}_{i}} \kappa^{\mathrm{A}_{j} \mathrm{~B}_{j}}}\left(\frac{\sqrt{\sigma_{i i} \sigma_{j j}}}{0.5\left(\sigma_{i i}+\sigma_{j j}\right)}\right)^{3}
\end{gathered}
$$

There is also a dipole-dipole component of the equation that depends on the dipole-moment and dipole-fraction parameters. The polar Helmholtz term depends on the second- and third-order terms in a Helmholtz perturbation expansion:

$$
A^{\text {polar }}=\frac{A_{2}}{1-\frac{A_{3}}{A_{2}}}
$$

where the second- and third-order perturbation expansions depend on the summation of the dipole-moment and dipole-fraction parameters over all species [24, 30]. Because the dipoledipole portion of the equation led to numerical instability when performing phase equilibria calculations, it was not used herein. Consequently, three pure-species parameters are required for non-hydrogen bonding systems $\left(\varepsilon_{i i}, \sigma_{i i}\right.$, and $\left.m_{i}\right)$, five pure-species parameters are required for hydrogen bonding systems $\left(\varepsilon_{i i}, \sigma_{i i}\right.$, and $\left.m_{i}, \kappa^{A i B j A}, \varepsilon^{A i B j}\right)$, and up to $3 N C$ binary parameters are required, where $N C$ is the number of species. The factor of 3 takes into account all binary parameters in Eq. 14.

\subsection{SAFT- $\gamma$ Mie}

An alternative to modeling molecules as chains of spherical segments is to model them as combinations of different functional groups. This approach has been used previously for both 
pure-species parameters (i.e., Joback or Marrero and Gani methods) [31] activity coefficient models (like UNIFAC) [32], and cubic EoS [33]. The advantages of this approach are that the assumption of perfectly spherical segments can be relaxed by introducing a shape factor, and parameters do not need to be regressed for every molecule in the system. As long as all of the functional groups in a molecule are known, the molecule's thermodynamic properties and behavior in mixtures can be predicted. This is useful for systems where large numbers of similar molecules are present, as is often seen in biological systems. When working with the biodiesel system, the group methodology is helpful to represent the large ranges of fatty-acid methyl-esters (FAMEs) and triglycerides.

The most recent implementation of the group-contribution methodology within the SAFT framework is in the SAFT- $\gamma$ Mie EoS [21]. Like PC-SAFT, SAFT- $\gamma$ Mie is formulated in terms of the Helmholtz free energy. However, the formulation is different as it involves terms for the monomeric functional-group interactions. The SAFT- $\gamma$ Mie equation is:

$$
\frac{A}{N k_{\mathrm{B}} T}=\frac{A^{\mathrm{ig}}}{N k_{\mathrm{B}} T}+\frac{A^{\text {mono }}}{N k_{\mathrm{B}} T}+\frac{A^{\text {chain }}}{N k_{\mathrm{B}} T}+\frac{A^{\text {assoc }}}{N k_{\mathrm{B}} T}
$$

where $A$ is the Helmholtz free energy, $N$ is the number of molecules, $k_{\mathrm{B}}$ is Boltzmann's constant, $T$ is the absolute temperature, $A^{\text {ig }}$ is the ideal gas contribution, $A^{\text {mono }}$ is the contribution of the individual functional groups, $A^{\text {chain }}$ is the contribution of the full molecules, and $A^{\text {assoc }}$ is the association contribution. Unlike PC-SAFT, there is no term to account for the dipole-dipole interactions that occur in molecules having lone electron pairs. However, since this term was set to zero in PC-SAFT, it allows a more symmetric comparison of the models.

Another major difference between the two SAFT EoSs, is that SAFT- $\gamma$ Mie replaces the square-well potential energy function with the Mie function (a generalized form of the LennardJones equation). The Mie potential energy function is displayed in:

$$
\begin{aligned}
& U_{k l}(r)=\Omega_{k l}^{\mathrm{Mie}} \varepsilon_{k l}\left[\left(\frac{\sigma_{k l}}{r}\right)^{\lambda_{R, k l}}-\left(\frac{\sigma_{k l}}{r}\right)^{\lambda_{a t, k l}}\right] \\
& \Omega_{k l}^{\mathrm{Mie}}=\frac{\lambda_{R, k l}}{\lambda_{R, k l} \lambda_{a t, k l}}\left(\frac{\lambda_{R, k l}}{\lambda_{a t, k l}}\right)^{\left(\frac{\lambda_{a t}, k l}{\lambda_{R, k l} \lambda_{a t, k l}}\right)}
\end{aligned}
$$

where $\sigma_{k l}$ is the group segment diameter, $\varepsilon_{k l}$ is the depth of the potential well between groups, $\lambda_{R, k l}$ and $\lambda_{a t, k l}$ are the repulsive and attractive exponents of the intergroup interactions, respectively, and $\Omega_{k l}$ is a function of $\lambda_{R, k l}$ and $\lambda_{a t, k l}$, which ensures that the minimum interaction energy is $\varepsilon_{k l}$. 
The hard-sphere diameter is calculated using Eq. 16, with the Mie potential replacing the square well potential used in PC-SAFT. However, unlike with the case of the square-well potential, Eq. 16 cannot be solved analytically for the Mie potential, and a Gauss-Legendre procedure has been applied [34] to allow incorporation into the code. As before, the hard-sphere diameter is used to calculate the reduced densities (Eq. 15), which are used in both the monomeric and chain contribution terms.

The monomer contribution in Eq. 22 is analogous to the hard-sphere and dispersion contributions from Eq. 11, but for functional groups instead of molecules. The dispersion contribution is also calculated using a perturbation expansion, but SAFT- $\gamma$ Mie uses a third-order perturbation expansion, compared with the second-order expansion in Eq. 17. The chain contribution is determined by calculating molecule-averaged quantities for $\sigma_{k l}, \varepsilon_{k l}, \lambda_{R, k l}, \lambda_{a t, k l}, D_{k}$, and $\zeta_{n}$. These averaged molecule parameters are used to calculate a pair potential function that is summed over the number of species to yield the chain contribution of the Helmholtz free energy. The association term is similar to Eq. 18, only its formulation is in terms of the associating sites per functional group, which is summed over the various molecules in the solution:

$$
\frac{A^{\text {assoc }}}{N k_{\mathrm{B}} T}=\sum_{i=1}^{N C} x_{i} \sum_{k=1}^{N G_{i}} n g_{k, i} \sum_{A=1}^{N_{S T, k}} n s g_{k, A}\left(\operatorname{Ln} X_{i, k, A}+\frac{1-X_{i, k, A}}{2}\right)
$$

where $N C$ is the number of chemical species, $N G_{i}$ is the number of groups for species $i$, $\operatorname{ng}_{k, \mathrm{i}}$ is the number of groups of type $k$ in molecule $i, N_{\mathrm{ST}, k}$ is the total number of site types on a given group $k$, and $n s g_{k, a}$ is the number of sites of type $A$ on group $k . X_{i, k, A}$ represents the fraction of molecules of species $i$ that are not bonded at a site of type $A$ on group $k$. $X_{i, k, A}$ is a complex function of $\varepsilon_{k l, A B}^{\mathrm{HB}}$ (the interaction energy between two bonding sites) and $r_{k l, A B}^{c}$ (the interaction range between two bonding sites) for associating sites $A$ and $B$ on groups $k$ and $l$ respectively. The potential energy function which characterizes the association energy is described by the square-well potential energy function:

$$
u_{k l, A B}^{H B}\left(r_{k l, A B}\right)=\left\{\begin{array}{lc}
-\varepsilon_{k l, A B}^{H B}, & r_{k l, A B} \leq r_{k l, A B}^{c} \\
0, & r_{k l, A B}>r_{k l, A B}^{c}
\end{array}\right.
$$

Overall, for each group, four like parameters need to be regressed for a non-associating system $\left(\sigma_{k k}, \varepsilon_{k k}, \lambda_{R, k k}, \lambda_{a t, k k}\right)$ and six like parameters need to be regressed for an associating system 
$\left(\sigma_{k k}, \varepsilon_{k k}, \lambda_{R, k k}, \lambda_{a t, k k}, \varepsilon_{k l, A B}^{\mathrm{HB}}, r_{k l, A B}^{\mathrm{c}}\right)$. The unlike parameters can either be regressed from data or calculated using the following equations:

$$
\begin{gathered}
\sigma_{k l}=\frac{1}{2}\left(\sigma_{k k}+\sigma_{l l}\right) \\
\varepsilon_{k l}=\frac{\sqrt{\sigma_{k k}^{3} \sigma_{l l}^{3}}}{\sigma_{k l}^{3}} \sqrt{\varepsilon_{k k} \varepsilon_{l l}} \\
\lambda_{R, k l}=3+\sqrt{\left(\lambda_{R, k k}-3\right)\left(\lambda_{R, l l}-3\right)} \\
\lambda_{a t, k l}=3+\sqrt{\left(\lambda_{a t, k k}-3\right)\left(\lambda_{a t, l l}-3\right)} \\
D_{k l}=\frac{1}{2}\left(D_{k k}+D_{l l}\right) \\
\varepsilon_{k l, A B}^{H B}=\sqrt{\varepsilon_{k k, A A}^{H B} \varepsilon_{l l, B B}^{H B}} \\
r_{k l, A B}^{H B}=\frac{1}{2}\left(r_{k k, A A}^{c}+r_{l l, B B}^{c}\right)
\end{gathered}
$$

Note that instead of Eq. 31, Eq. 16 could be used to calculate the unlike hard-sphere diameter. However, Eq. 31 is used to decrease the numerical complexity. It is also important to realize that while it appears that SAFT- $\gamma$ Mie requires many more parameters than PC-SAFT (4 compared to 3 for non-associating systems, or 6 compared to 5 for associating systems), the SAFT- $\gamma$ Mie parameters are for groups, which can be used for multiple molecules. SAFT- $\gamma$ Mie also does not require separate binary parameters $\left(K_{i j}\right)$, which further decreases the number of regressed parameters required for complex systems.

\subsection{Tangent-Plane-Distance Criterion}

The equations-of-state are used to calculate thermodynamic properties, such as fugacity coefficients and liquid molar volumes. However, determining the phase distribution and compositions in a multiphase mixture requires that the Gibbs free energy be minimized subject to mass-balance constraints [35-39]. For this purpose, the Gibbs flash method ${ }^{2}$ in ASPEN PLUS was used [35, 38] with PC-SAFT and RK-ASPEN, and a proprietary algorithm was used in gPROMS. While, with good initial guesses, it is possible to find the correct phase distribution through direct minimization of the Gibbs free energy [40], it is preferable to check the stability

\footnotetext{
${ }^{2}$ Two flash convergence algorithms are available: "Inside-Out" (Boston and Britt, 1976) and direct minimization of Gibbs free energy (Gautam and Seider, 1979). The former is implemented in the FLASH2 and FLASH3 blocks and the latter in the RGIBBS block. To our knowledge, the latter uses an approximate phase-splitting algorithm as the free energy is minimized.
} 
of the resulting phases by using the Gibbs free energy of mixing to estimate the tangent-planedistance function [41-43]. The tangent-plane-distance function compares the total Gibbs free energy after creating a new, infinitesimal phase with the Gibbs free energy of the initial phase, shown as Eq. 34, where $\Delta G$ is the total Gibbs free energy of the phase, $\bar{Z}$ is the vector of moles in the initial phase, and $\bar{Y}$ is the vector of moles in the infinitesimal phase. This expression can be reformulated in terms of the Gibbs free energies of mixing as Eq. 35 [43], where $\bar{y}$ is the vector of mole fractions in the infinitesimal phase, $\bar{z}$ is the vector of mole fractions in the initial phase, $\Delta G_{\mathrm{m}}(\bar{y})$ is the Gibbs free energy mixing surface, $\Delta G_{\mathrm{m}}^{\mathrm{T}}(\bar{z})$ is the tangent plane, and $F(\bar{y})$ is the tangent-plane-distance function (the difference between the tangent plane and the Gibbs free energy of mixing surface). If $F(\bar{y})$ is greater than zero for all values of $\bar{y}$, the initial phase is stable. Otherwise, the initial phase is unstable, guesses for another phase are estimated, and the Gibbs free energy is re-minimized.

A more common formulation of the tangent-plane-distance function is shown as Eq. 36, where $\mu_{i}$ is the chemical potential of species $i$ in the phase [43]. Finally, the tangent-planedistance function is reformulated using Eq. 37 and 38 to give Eq. 39, where $\mu_{i, r e f}$ is the chemical potential of species $i$ in the pure ideal gas evaluated at $T, R$ is the gas constant, $T$ is the absolute temperature, $f_{\mathrm{i}}$ is the fugacity of species $i$ in the phase, $P$ is the pressure of the system, $\phi_{i}$ is the fugacity coefficient of species $i$ in the phase, $x_{i}$ is the mole fraction of species $i$ in the phase, and $\phi_{o, i}$ is the fugacity coefficient of species $i$ in the original phase.

Eq. 39 is used herein in a FORTRAN algorithm written by Prof. Romain Privat [44], which examines the stability of every phase separately. The code uses the objective function, $\Phi$, defined by Michelsen [42], in Eq. 40, where $W_{i}$ is the non-normalized concentration for the infinitesimal phase. Since the minimum of the objective function satisfies the necessary constraint [42], Eq. 41 - the minimum can be found by minimizing the sum of the squares, shown in Eq. 42. The objective function, $\Gamma$, is minimized using a custom-written NLP solver with numerous initial guesses. If the minimum of Eq. 39 is found to be negative, the initial phase(s) is unstable. Otherwise, the phase(s) is assumed to be stable. This code was incorporated within ASPEN PLUS by the authors, permitting $\phi_{i}$ and $\phi_{o, i}$ to be calculated using the ASPEN PLUS physical property system. 


$$
\begin{aligned}
& \Delta G(\bar{Y})=\Delta G(\bar{Z}-\bar{Y})+\Delta G(\bar{Y})-\Delta G(\bar{Z}) \geq 0, \forall \bar{Y} \\
& F(\bar{y})=\Delta G_{m}(\bar{y})-\Delta G_{m}^{T}(\bar{z}) \geq 0, \forall \bar{y} \\
& F(\bar{y})=\sum_{i=1}^{N C} y_{i}\left(\mu_{i}(\bar{y})-\mu_{i}(\bar{z})\right) \geq 0, \forall \bar{y} \\
& \mu_{i}=\mu_{i, r e f}+R T \operatorname{Ln}\left(f_{i}\right) \\
& f_{i}=P \phi_{i} x_{i} \\
& F(\bar{y})=R T \sum_{i=1}^{N C} y_{i}\left(\operatorname{Ln}\left(y_{i}\right)+\operatorname{Ln}\left(\phi_{i}\right)-\operatorname{Ln}\left(z_{i}\right)-\operatorname{Ln}\left(\phi_{o, i}\right)\right) \\
& \Phi(T, P, z, W)=1+\sum_{i=1}^{N C} W_{i} *\left(\operatorname{Ln}\left(W_{i}\right)+\operatorname{Ln}\left(\phi_{i}\right)-\operatorname{Ln}\left(z_{i} \phi_{o, i}\right)-1\right) \\
& \operatorname{Ln}\left(W_{i}\right)+\operatorname{Ln}\left(\phi_{i}\right)-\operatorname{Ln}\left(z_{i} \phi_{o, i}\right)=0, \forall i \\
& \Gamma(T, P, z, W)=\sum_{i=1}^{N C}\left(\operatorname{Ln}\left(W_{i}\right)+\operatorname{Ln}\left(\phi_{i}\right)-\operatorname{Ln}\left(z_{i} \phi_{o, i}\right)\right)^{2}
\end{aligned}
$$

\section{Experimental}

\subsection{Vapor-Liquid Equilibria}

Methyl-oleate and methanol equilibrium data were measured using a $500 \mathrm{~mL}$ bulb connected to a condenser and setup for total or partial reflux. The bulb was heated with an electric heating jacket, and the cooling water was circulated at $7^{\circ} \mathrm{C}$. The well-insulated apparatus was mixed by a magnetic stir bar in the liquid phase and heated to obtain a low boil. The system was then operated at total reflux for 1-hour to attain equilibrium. A small sample of the condensed vapor was collected using a 3-way valve. The liquid was sampled from a stopcock at the bottom of the bulb. Following sampling, methanol was added through the condenser to obtain data at a higher methanol composition.

\subsection{Liquid-Liquid Equilibria}

Each species was added at equal mass loadings to a $10 \mathrm{~mL}$ separatory funnel that was used for equilibration and sampling. The apparatus was affixed to a rotisserie-style rotor inside a preheated oven and rotated for at least 3 hours to provide adequate contact between the two liquids. The samples were then left to equilibrate for at least 5 hours. The top phase was sampled using a pipette and the bottom phase was sampled through the funnel's stopcock. During sampling, the first few drops of sample were discarded to insure a representative sample was taken. All experiments were run at least in duplicate. 


\subsection{Sample Preparation}

To obtain the methyl-oleate concentration, samples were diluted in heptane containing $0.05 \mathrm{~g} / \mathrm{L}$ of methyl-laurate as an internal standard. For the analysis of triolein, samples were diluted in 1:1 chloroform:methanol containing $0.1 \mathrm{~g} / \mathrm{L}$ tripalmitin as an internal standard. They were then transesterified using $14 \%$ boron trifluoride in methanol. The sample headspace was sparged with nitrogen, and the reaction took place at $100^{\circ} \mathrm{C}$ for 1 -hour. The reacted samples were diluted with heptane containing $0.05 \mathrm{~g} / \mathrm{L}$ of methyl-laurate as an internal standard. For analysis of glycerol, samples were silylated using ASTM Standard test method D6584 - 13 [45].

\subsection{Analysis}

The sample analysis was performed using a Perkin-Elmer AutoSystem XL Gas Chromatograph and Gold Mass Spectrometer (GC-MS). The GC was fitted with a $15 \mathrm{~m} \times$ $0.25 \mathrm{~mm} \times 0.25 \mu \mathrm{m} 5 \%$ phenyl polydimethylsiloxane column (Agilent, DB-5ht) and joined with a $5 \mathrm{~m} \times 0.53 \mathrm{~mm}$ deactivated, Hi-Temp guard column using a press fit union. All analytical samples were run on the GC-MS using ASTM Standard test method D6584 - 13 [45]. Methyloleate and silylated glycerol were analyzed at a mass-to-charge ratio $(\mathrm{m} / \mathrm{z})$ of 264 and 205 with retention times of 11.00 and 5.87 minutes, respectively. The results of the analysis are shown as Appendix A.

\section{Regression Methodology}

This section discusses the techniques used to regress the pure-species and binaryinteraction parameters necessary for PC-SAFT in ASPEN PLUS and SAFT- $\gamma$ Mie in gPROMS. The same pure-species and binary data sets were used to regress parameters in both PC-SAFT and SAFT- $\gamma$ Mie. The Britt-Luecke method [46] in ASPEN PLUS was used to regress the parameters for PC-SAFT. The Levenberg-Marquardt algorithm [47] was used in gPROMS for SAFT- $\gamma$ Mie.

\section{1. $\quad$ Pure Species}

The majority of the pure-species data were obtained from the NIST database within ASPEN PLUS [48]. For methyl-oleate [49-52], glycerol [53, 54], $\mathrm{CO}_{2}$ [55], and triolein [56, 57], sufficient data were not present in the NIST databanks. Supplementary data were obtained from 
the literature [58-60]. For all species except carbon dioxide, liquid density and liquid vaporpressure data were used to regress the pure-species parameters. Liquid density data were weighted more heavily (roughly 200 times) than vapor-pressure data, leading to more accurate representation of liquid phase behavior, and in particular liquid-liquid equilibria. The liquid phase behavior must be accurate, because in a biodiesel production reactor, the reactions occur exclusively in the liquid phases (and only at the surface of a catalyst bead) due to the nonvolatile triglycerides. It is also essential to capture the liquid-liquid behavior of the aqueous (methanol) phase and the nonpolar (oil) phase to obtain an accurate prediction of the reaction rates.

With regard to carbon dioxide, the pure-species parameters were regressed entirely from densities for the three phases (vapor, liquid, and supercritical). Because ASPEN PLUS accepts data input as either a vapor or a liquid phase, the supercritical region needed to be partitioned into these two categories. Densities greater than the critical density $\left(467.6 \mathrm{~kg} / \mathrm{m}^{3}\right)$ [61] were classified as liquid, while all others were classified as vapor. Plots of the density as a function of temperature were also generated to visualize the phase distribution, as shown in Figure 2. From these, good agreement between the data points and the PC-SAFT method is observed.

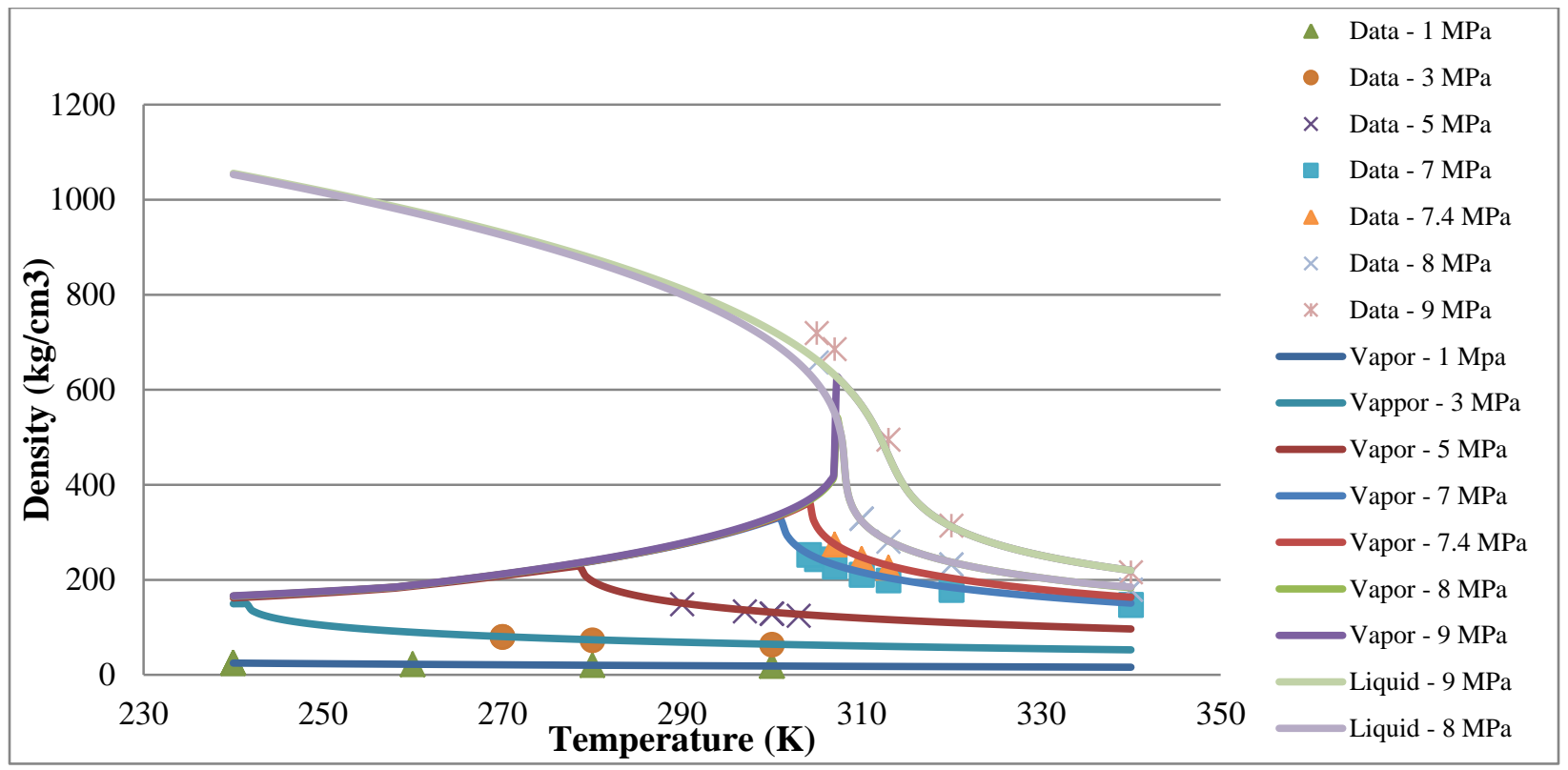

Figure 2. $\mathrm{CO}_{2}$ density as a function of temperature using the PC-SAFT EoS

\subsection{Binary}

Binary data were obtained from the NIST interface in ASPEN PLUS [48], the literature [62-64], as well as the experiments in Section 3 (data listed in Appendix A). The regressed 
binary interaction parameters for PC-SAFT are shown below. Only $b_{i, j}$ and $c_{i, j}$ were regressed, with the others set to zero. For SAFT- $\gamma$ Mie, the cross-interaction energies for unlike groups, $\varepsilon_{i j}$, were regressed using binary data. In some cases, unlike well-distance parameters, $\lambda_{i j}$, were added to improve the fit.

$$
\begin{gathered}
\varepsilon_{i j}=\left(1-K_{i, j}\right) \sqrt{\varepsilon_{i} \varepsilon_{j}} \\
K_{i, j}=a_{i, j}+\frac{b_{i, j}}{T_{r}}+c_{i, j} \operatorname{Ln}\left(T_{\mathrm{r}}\right)+d_{i, j} T_{\mathrm{r}}+e_{i, j} T_{\mathrm{r}}^{2} \\
T_{\mathrm{r}}=\frac{T}{T_{\text {ref }}}
\end{gathered}
$$

where $\varepsilon_{i, j}$ is the square-well potential energy constant for two unlike molecules $i$ and $j$, $\varepsilon_{\mathrm{i}}$ and $\varepsilon_{\mathrm{j}}$ are the square-well potential energy constants for pure species $i$ and $j$, respectively, $K_{i, j}$ is the binary interaction parameter for molecules $i$ and $j, a_{i, j}, b_{i, j}, c_{i, j}, d_{i, j}$, and $e_{i, j}$ are empirical constants that are fit to binary data for molecules $i$ and $j, T_{\mathrm{r}}$ is the reduced temperature, $T$ is the system temperature, and $T_{\text {ref }}$ is the chosen reference temperature (298.15 K).

\section{Results}

\subsection{Parameter Results}

The pure-species PC-SAFT parameters are shown in Table 1. A similar set of parameters were regressed for SAFT- $\gamma$ Mie (the gSAFT package in gPROMS); however, at this time, those parameters cannot be released for intellectual property reasons. The groups that were used by SAFT- $\gamma$ Mie are shown in Table 2. Where "R" represents a set of parameters that were regressed from data herein, " $P$ " represents a set of parameters that were regressed in earlier work, and " $X$ " indicates no parameters were regressed, because the necessary data does not exist.

In Table 1, PCSFTM is $m_{i}$ in Eq. 15, representing the length of the molecule. Note that fits are empirical and while they follow a logical trend, the parameter values presented herein are not meant to agree with theoretical molecular properties. PCSFTU is the interaction energy, $\varepsilon_{i}$. PCSFTV is the characteristic diameter, $\sigma_{i}$. PCSFAU is the association site interaction energy (for hydrogen bonding molecules), $\varepsilon^{\mathrm{A}_{i} \mathrm{~B}_{i}}$. PCSFAV is the association site interaction volume (for hydrogen-bonding molecules), $\kappa^{\mathrm{A}_{i} \mathrm{~B}_{i}}$. PCSFMU and PCSFXP are the characteristic dipolemoment and the characteristic dipole-fraction parameters, respectively. The latter two 
parameters are not used herein because they led to numerical instability for regressions and simulations. The effect of lone pairs was not accounted for in SAFT- $\gamma$ Mie for similar reasons.

Table 1. Pure-Species Parameters for PC-SAFT

\begin{tabular}{|c|c|c|c|c|c|c|c|c|}
\hline \multicolumn{9}{|c|}{ PURE COMPONENT } \\
\hline Parameters & $\begin{array}{l}\text { ASPEN } \\
\text { PLUS } \\
\text { Name }\end{array}$ & Units & Component & Component & Component & Component & Component & Component \\
\hline & & & $\begin{array}{c}\text { Methyl- } \\
\text { oleate }\end{array}$ & Triolein & Glycerol & Methanol & Water & $\begin{array}{l}\text { Carbon } \\
\text { dioxide }\end{array}$ \\
\hline$m_{i}$ & PCSFTM & - & 9.0390 & 16.184 & 2.1512 & 0.55347 & 0.33444 & 1.8102 \\
\hline$\varepsilon_{i}$ & PCSFTU & $\mathrm{K}$ & 248.47 & 282.84 & 472.16 & 120.97 & 139.50 & 179.83 \\
\hline$\sigma_{i}$ & PCSFTV & - & 3.7465 & 4.4475 & 3.7517 & 4.6043 & 4.5938 & 2.9107 \\
\hline$\varepsilon^{A i B i}$ & PCSFAU & $\mathrm{K}$ & 0 & 0 & 3832.4 & 3602.3 & 3965.5 & 0 \\
\hline$\kappa^{A i B i}$ & PCSFAV & - & 0 & 0 & 0.00189 & 0.01171 & 0.00634 & 0 \\
\hline$\mu$ & PCSFMU & - & 0 & 0 & 0 & 0 & 0 & 0 \\
\hline$X_{\mathrm{p}}$ & PCSFXP & - & 0 & 0 & 0 & 0 & 0 & 0 \\
\hline
\end{tabular}

Table 2. SAFT- $\gamma$ Mie groups.

\begin{tabular}{|c|c|c|c|c|c|c|c|c|c|}
\hline Group & $\mathrm{CH}_{3}$ & $\mathrm{CH}_{2}$ & $\mathrm{CH}=$ & $\mathrm{COO}$ & $\mathrm{C}_{9} \mathrm{H}_{11} \mathrm{O}_{6}$ & $\mathrm{C}_{3} \mathrm{H}_{8} \mathrm{O}_{3}$ & $\mathrm{CO}_{2}$ & $\mathrm{CH}_{3} \mathrm{OH}$ & $\mathrm{H}_{2} \mathrm{O}$ \\
\hline $\mathrm{CH}_{3}$ & $\mathrm{P}$ & $\mathrm{P}$ & $\mathrm{P}$ & $\mathrm{R}$ & $\mathrm{R}$ & $\mathrm{R}$ & $\mathrm{R}$ & $\mathrm{R}$ & $\mathrm{R}$ \\
\hline $\mathrm{CH}_{2}$ & $\mathrm{P}$ & $\mathrm{P}$ & $\mathrm{P}$ & $\mathrm{R}$ & $\mathrm{R}$ & $\mathrm{R}$ & $\mathrm{R}$ & $\mathrm{R}$ & $\mathrm{R}$ \\
\hline $\mathrm{CH}=$ & $\mathrm{P}$ & $\mathrm{P}$ & $\mathrm{P}$ & $\mathrm{R}$ & $\mathrm{R}$ & $\mathrm{R}$ & $\mathrm{R}$ & $\mathrm{R}$ & $\mathrm{R}$ \\
\hline $\mathrm{COO}$ & $\mathrm{R}$ & $\mathrm{R}$ & $\mathrm{R}$ & $\mathrm{R}$ & $X$ & $\mathrm{R}$ & $\mathrm{R}$ & $\mathrm{R}$ & $\mathrm{R}$ \\
\hline $\mathrm{C}_{9} \mathrm{H}_{11} \mathrm{O}_{6}$ & $\mathrm{R}$ & $\mathrm{R}$ & $\mathrm{R}$ & $X$ & $\mathrm{R}$ & $\mathrm{R}$ & $\mathrm{R}$ & $\mathrm{R}$ & $\mathrm{R}$ \\
\hline $\mathrm{C}_{3} \mathrm{H}_{8} \mathrm{O}_{3}$ & $\mathrm{R}$ & $\mathrm{R}$ & $\mathrm{R}$ & $\mathrm{R}$ & $\mathrm{R}$ & $\mathrm{R}$ & $X$ & $\mathrm{R}$ & $\mathrm{R}$ \\
\hline $\mathrm{CO}_{2}$ & $\mathrm{P}$ & $\mathrm{P}$ & $\mathrm{P}$ & $\mathrm{R}$ & $\mathrm{R}$ & $X$ & $\mathrm{R}$ & $\mathrm{R}$ & $\mathrm{R}$ \\
\hline $\mathrm{CH}_{3} \mathrm{OH}$ & $\mathrm{P}$ & $\mathrm{P}$ & $\mathrm{P}$ & $\mathrm{R}$ & $\mathrm{R}$ & & $\mathrm{R}$ & $\mathrm{R}$ & $\mathrm{R}$ \\
\hline $\mathrm{H}_{2} \mathrm{O}$ & $\mathrm{P}$ & $\mathrm{P}$ & $\mathrm{P}$ & $\mathrm{R}$ & $\mathrm{R}$ & $\mathrm{R}$ & $\mathrm{R}$ & $\mathrm{R}$ & $\mathrm{R}$ \\
\hline
\end{tabular}

The binary interaction parameters regressed from vapor-liquid and liquid-liquid equilibria data are shown in Tables 3 and 4 . Only $b_{i j}$ and $c_{i j}$ (in Eq. 44) were regressed to avoid overregressing parameters. 
Table 3. Binary-Species Parameters for PC-SAFT (from VLE data)

\begin{tabular}{|c|c|c|c|c|}
\hline Species $i$ & Methanol & Glycerol & Glycerol & Water \\
\hline Species $j$ & Carbon Dioxide & Methanol & Water & Methanol \\
\hline $\begin{array}{c}\text { Temp. } \\
\text { units }\end{array}$ & ${ }^{\circ} \mathrm{C}$ & ${ }^{\circ} \mathrm{C}$ & ${ }^{\circ} \mathrm{C}$ & ${ }^{\circ} \mathrm{C}$ \\
\hline$a_{i, j}$ & 0 & 0 & 0 & 0 \\
\hline$b_{i, j}$ & -0.1317 & -0.3297 & 0.21467 & -0.5846 \\
\hline$c_{i, j}$ & 0.3591 & -0.1476 & -1.6503 & 2.7260 \\
\hline$d_{i, j}$ & 0 & 0 & 0 & 0 \\
\hline$e_{i, j}$ & 0 & 0 & 0 & 0 \\
\hline$T_{\text {ref }}$ & 25 & 25 & 25 & 25 \\
\hline \multicolumn{5}{|c|}{} \\
\hline Species $i$ & Carbon Dioxide & Methanol & $\mathrm{CO}_{2}$ & $\mathrm{CO}_{2}$ \\
\hline Species $j$ & Water & $\begin{array}{c}\text { Methyl- } \\
\text { oleate }\end{array}$ & ${ }^{\mathrm{FAME}}$ & ${ }^{\mathrm{TG}}$ \\
\hline $\begin{array}{c}\text { Temp. } \\
\text { units }\end{array}$ & ${ }^{\circ} \mathrm{C}$ & ${ }^{\circ} \mathrm{C}$ & ${ }^{\circ} \mathrm{C}$ & ${ }^{\circ} \mathrm{C}$ \\
\hline$a_{i, j}$ & 0 & 0 & 0 & 0 \\
\hline$b_{i, j}$ & -0.4504 & -0.1658 & -0.0429 & 0.13616 \\
\hline$c_{i, j}$ & -0.0191 & -1.463 & 1.0185 & 0.29994 \\
\hline$d_{i, j}$ & 0 & 0 & 0 & 0 \\
\hline$e_{i, j}$ & 0 & 0 & 0 & 0 \\
\hline$T_{\text {ref }}$ & 25 & 25 & 25 & 25 \\
\hline
\end{tabular}

The pure-species parameters for RK-ASPEN are in Table 5. They were taken from the NIST databank, with the exception of triolein, which decomposes before reaching its critical point. Consequently, its critical properties were generated using group-contribution methods [3, 4, 8]. The binary interaction parameters (in Eqs. 8 and 9) are in Table 6. They were regressed using the same data and algorithm as for those in PC-SAFT.

\section{2. $\quad$ Pure Species}

Figure 3 shows the plots of pure-species liquid densities and vapor pressures for triolein, with similar plots for water, methanol, glycerol, and methyl-oleate in Figures S1-S4 in the 
Supplement to this paper. In these plots, pure component properties were generated over the range of temperatures and pressures for each species using PC-SAFT, SAFT- $\gamma$ Mie (gSAFT), and RK-ASPEN. All three EoS provide excellent agreement with vapor pressures, with the exception of triolein; however, the cubic EoS (RK-ASPEN), yields poor predictions of liquid densities. This underestimation of liquid density by RK-ASPEN would lead to drastic underestimations of process-vessel sizes.

Table 4. Binary-Species Parameters for PC-SAFT (from LLE data)

\begin{tabular}{|c|c|c|c|c|c|}
\hline Species $i$ & Triolein & $\begin{array}{c}\text { Methyl- } \\
\text { oleate }\end{array}$ & $\begin{array}{c}\text { Methyl- } \\
\text { oleate }\end{array}$ & Triolein & Triolein \\
\hline Species $j$ & Methanol & Water & Glycerol & Glycerol & Water \\
\hline $\begin{array}{c}\text { Temp. } \\
\text { units }\end{array}$ & ${ }^{\circ} \mathrm{C}$ & ${ }^{\circ} \mathrm{C}$ & ${ }^{\circ} \mathrm{C}$ & ${ }^{\circ} \mathrm{C}$ & ${ }^{\circ} \mathrm{C}$ \\
\hline$a_{i, j}$ & 0 & 0 & 0 & 0 & 0 \\
\hline$b_{i, j}$ & -0.06820 & -0.31655 & -0.03783 & -0.10413 & -0.17356 \\
\hline$c_{i, j}$ & 0.01725 & -0.12144 & 0.01543 & -0.01823 & 0.20112 \\
\hline$d_{i, j}$ & 0 & 0 & 0 & 0 & 0 \\
\hline$e_{i, j}$ & 0 & 0 & 0 & 0 & 0 \\
\hline$T_{\text {ref }}$ & 25 & 25 & 25 & 25 & 25 \\
\hline
\end{tabular}

Table 5. Pure-Species Parameters for RK-ASPEN

\begin{tabular}{|c|c|c|c|c|c|c|c|}
\hline Parameters & Units & Component & Component & Component & Component & Component & Component \\
\hline & & $\begin{array}{c}\text { Methyl- } \\
\text { oleate }\end{array}$ & Water & Methanol & Triolein & Glycerol & $\mathrm{CO}_{2}$ \\
\hline$\omega$ & - & 0.96055 & 0.34407 & 0.55850 & 1.6862 & 0.55381 & 0.22567 \\
\hline$V_{\mathrm{C}}$ & $\mathrm{m}^{3} / \mathrm{kmol}$ & 1.2339 & 0.05870 & 0.11800 & 3.0070 & 0.24470 & 0.09431 \\
\hline$P_{\mathrm{C}}$ & $\mathrm{Pa}$ & $1.1726 \mathrm{E}+06$ & $2.2094 \mathrm{E}+07$ & $8.0099 \mathrm{E}+06$ & $4.6820 \mathrm{E}+05$ & $7.5025 \mathrm{E}+06$ & $7.3817 \mathrm{E}+06$ \\
\hline$T_{\mathrm{C}}$ & $\mathrm{K}$ & 768.00 & 647.11 & 512.70 & 947.10 & 850.00 & 304.16 \\
\hline
\end{tabular}

In Figure 4, liquid, vapor, and supercritical phase densities of $\mathrm{CO}_{2}$ are plotted as a function of pressure at various temperatures. Both versions of the SAFT EoS show excellent agreement with the data in all three regimes (vapor, liquid, and supercritical). By contrast, RKASPEN is accurate in the vapor regimes and at temperatures far above the critical region, which limits its ability to predict gas-expanded liquid (GXL) [65] systems. 
Table 6. Binary Interaction Parameters for RK-ASPEN (using VLE or LLE data)

\begin{tabular}{|c|c|c|c|c|c|c|c|}
\hline$K_{\mathrm{a}, i j}^{1}$ & Glycerol & Water & 0.0815 & $K_{\mathrm{a}, i j}^{1}$ & Glycerol & MEOH & 0.0049 \\
\hline$K_{\mathrm{b}, i j}^{1}$ & Glycerol & Water & 0.1925 & $K_{\mathrm{b}, i j}^{1}$ & Glycerol & MEOH & 0.0380 \\
\hline$K_{\mathrm{a}, i j}^{1}$ & $\begin{array}{c}\text { Methyl- } \\
\text { oleate }\end{array}$ & Water & -4.8307 & $K_{\mathrm{a}, i j}^{1}$ & $\begin{array}{c}\text { Methyl- } \\
\text { oleate }\end{array}$ & MEOH & -1.3533 \\
\hline$K_{\mathrm{b}, i j}^{1}$ & $\begin{array}{c}\text { Methyl- } \\
\text { oleate }\end{array}$ & Water & -1.6375 & $K_{\mathrm{b}, i j}^{1}$ & $\begin{array}{c}\text { Methyl- } \\
\text { oleate }\end{array}$ & MEOH & -0.6083 \\
\hline$K_{\mathrm{a}, i j}^{1}$ & Water & Methanol & 0.1295 & $K_{\mathrm{a}, i j}^{1}$ & Water & $\mathrm{CO}_{2}$ & -1.9801 \\
\hline$K_{\mathrm{b}, i j}^{1}$ & Water & Methanol & 0.3595 & $K_{\mathrm{b}, i j}^{1}$ & Water & $\mathrm{CO}_{2}$ & -0.9809 \\
\hline$K_{\mathrm{a}, i j}^{1}$ & Methanol & $\mathrm{CO}_{2}$ & 0.2373 & $K_{\mathrm{a}, i j}^{1}$ & $\mathrm{CO}_{2}$ & FAME & 0.1983 \\
\hline$K_{\mathrm{b}, i j}^{1}$ & Methanol & $\mathrm{CO}_{2}$ & 0.0316 & $K_{\mathrm{b}, i j}^{1}$ & $\mathrm{CO}_{2}$ & FAME & -0.2123 \\
\hline$K_{\mathrm{a}, i j}^{1}$ & $\mathrm{CO}_{2}$ & Triolein & 0.2086 & $K_{\mathrm{a}, i j}^{1}$ & Methanol & T-OLE & -1.7758 \\
\hline$K_{\mathrm{b}, i j}^{1}$ & $\mathrm{CO}_{2}$ & Triolein & 0.1955 & $K_{\mathrm{b}, i j}^{1}$ & Methanol & T-OLE & -0.7823 \\
\hline$K_{\mathrm{a}, i j}^{1}$ & $\begin{array}{c}\text { Methyl- } \\
\text { oleate }\end{array}$ & Glycerol & -11.177 & $K_{\mathrm{a}, i j}^{1}$ & Glycerol & T-OLE & -1.1270 \\
\hline$K_{\mathrm{b}, i j}^{1}$ & $\begin{array}{c}\text { Methyl- } \\
\text { oleate }\end{array}$ & Glycerol & -8.2022 & $K_{\mathrm{b}, i j}^{1}$ & Glycerol & T-OLE & -0.7685 \\
\hline$K_{\mathrm{a}, i j}^{1}$ & Triolein & Water & 97.529 & & & & \\
\hline$K_{\mathrm{b}, i j}^{1}$ & Triolein & Water & -11.754 & & & & \\
\hline
\end{tabular}

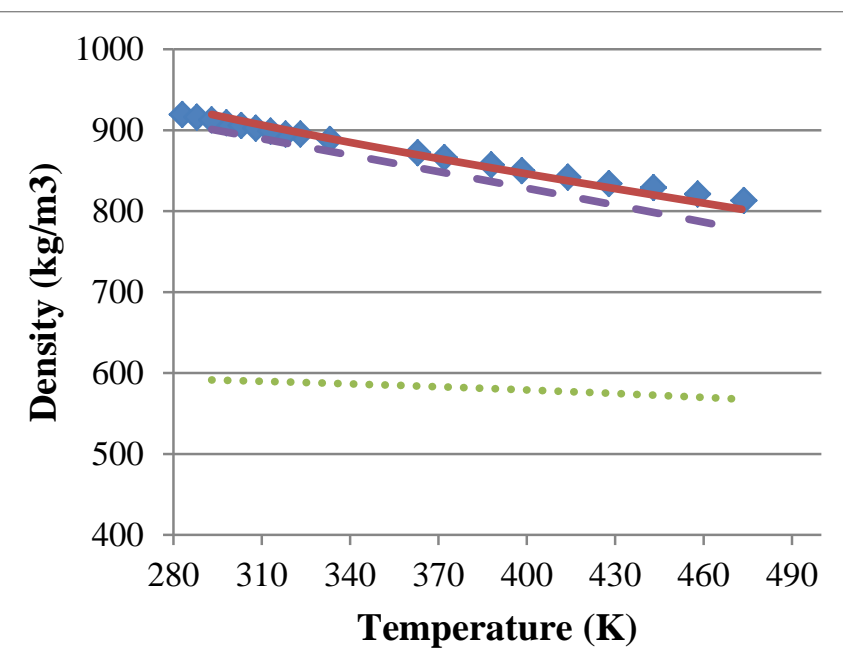

Data $\ldots .$. RK-ASPEN PC-SAFT - gSAFT

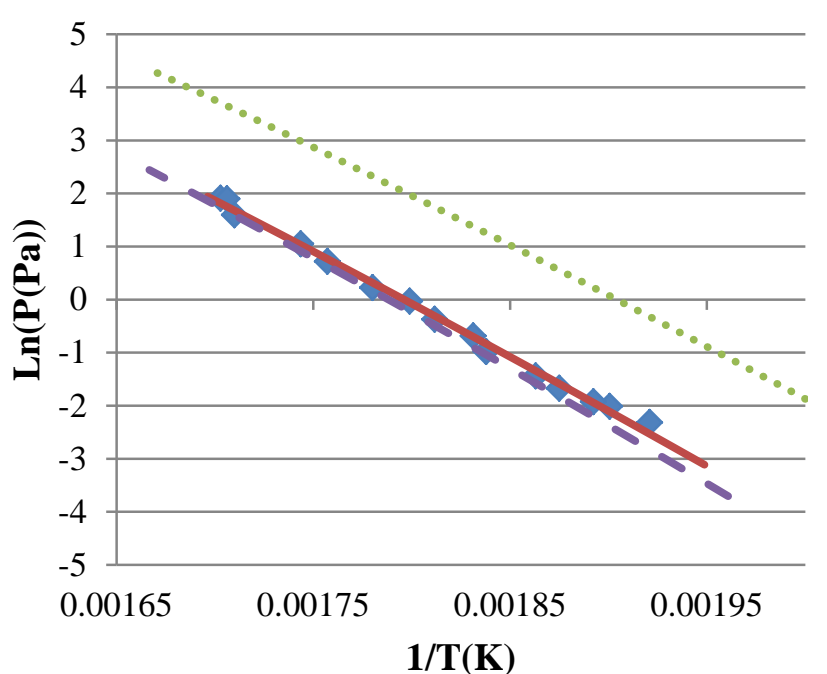

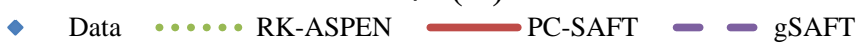

(a) Liquid density

(b) Liquid vapor pressure

Figure 3. Triolein properties 


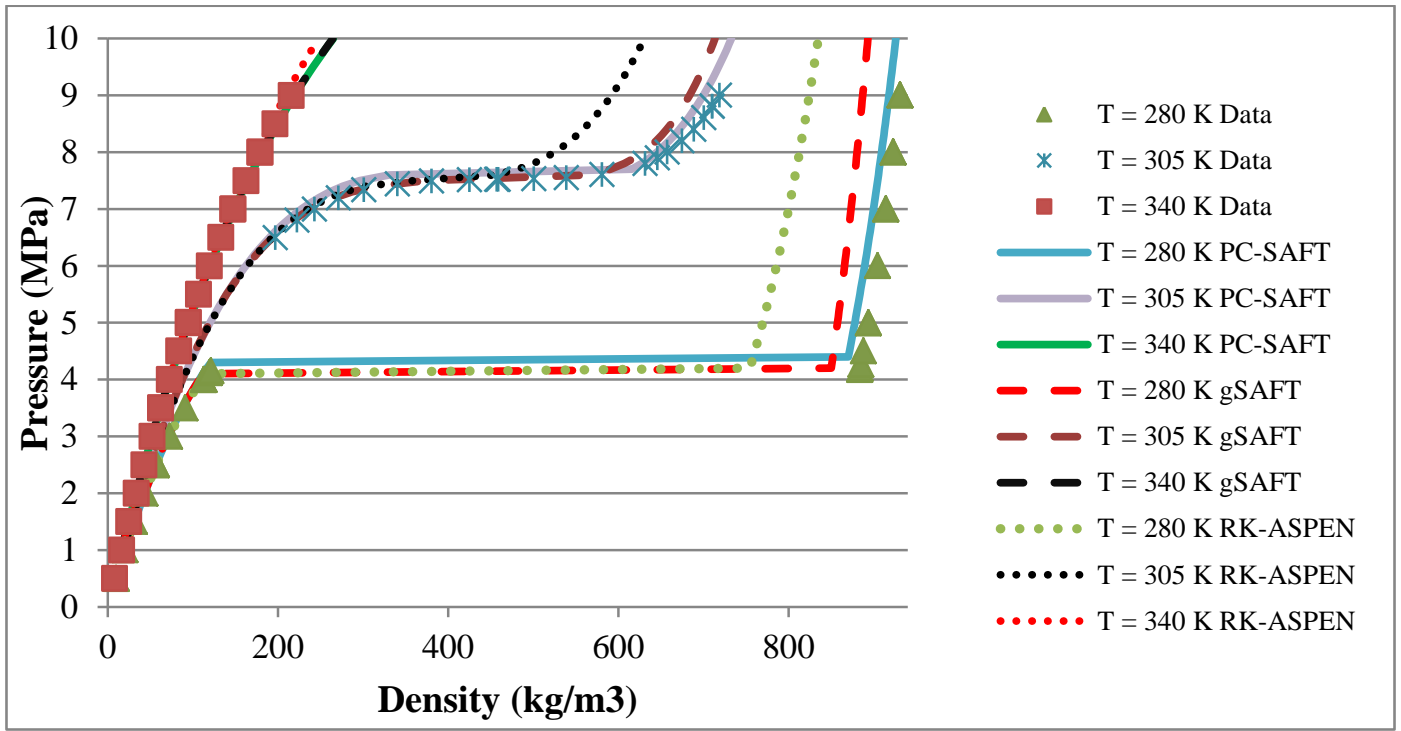

Figure 4. $\mathrm{CO}_{2}$ densities (see color e-copy to distinguish curves)

\subsection{Binary VLE Mixtures}

Figures 5-8 show bubble- and dew-point curves for binary mixtures involving the six species in the biodiesel system considered herein. Note that more binary VLE plots are listed in the Supplement (Figures S6-S9). For systems that do not involve $\mathrm{CO}_{2}$ (Figures S6-S8), the data are in excellent agreement with all three equations-of-state. Note that one of the systems, water and CO2, was also studied using the soft-SAFT EoS, and a similar level of agreement was obtained [16].

Introducing $\mathrm{CO}_{2}$ drives the mixtures toward their critical points, which are more difficult to model in the critical region. RK-ASPEN performs well for $\mathrm{CO}_{2}$ and methanol (Figure 6) because the molecules are small and do not associate. All of the EoSs perform somewhat poorly for triolein and $\mathrm{CO}_{2}$ around $313 \mathrm{~K}$ because of the proximity to the $\mathrm{CO}_{2}$ critical point and the sizedifference of the molecules. At higher temperatures, the EoSs are in much closer agreement with the data. The same effect is seen for FAME and $\mathrm{CO}_{2}$ around the critical point, although even in this region, gSAFT performs well. Note that the methyl-oleate and $\mathrm{CO}_{2}$ system was also studied using the soft-SAFT EoS, with a high level of agreement (comparable to that of gSAFT) obtained [16]. For Figure 8c, PC-SAFT yields poor performance, likely due to the high emphasis on liquid phase behavior using weighting factors. While the same weighting factors were used for SAFT- $\gamma$ Mie for the groups regressed herein, it was less sensitive to the effects of 
weighting because certain groups (like $\mathrm{CH}_{3}$ and $\mathrm{CH}_{2}$ ) had already been regressed previously and were not weighted.

Overall, the largest advantage of a SAFT EoS relative to a cubic EoS arises for the longchain species (triolein and methyl-oleate) in Figures 7 and 8. RK-ASPEN gave comparable performance for small molecules (for example, methanol and water); however, RK-ASPEN fails to accurately model the behavior of long-chain molecules as seen in Figures 7a, c, and 8 (but, not 7b). It should be noted that alpha factors were not used herein to improve RK-ASPEN's behavior, because it was meant to be a benchmark against previous calculations $[3,4,8]$.

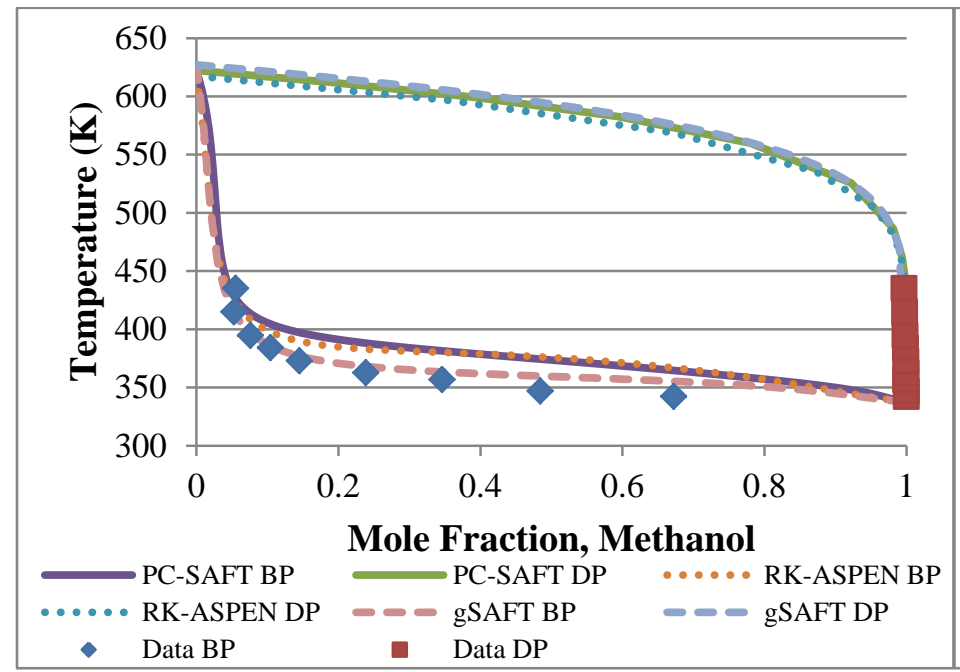

(a) Full-scale

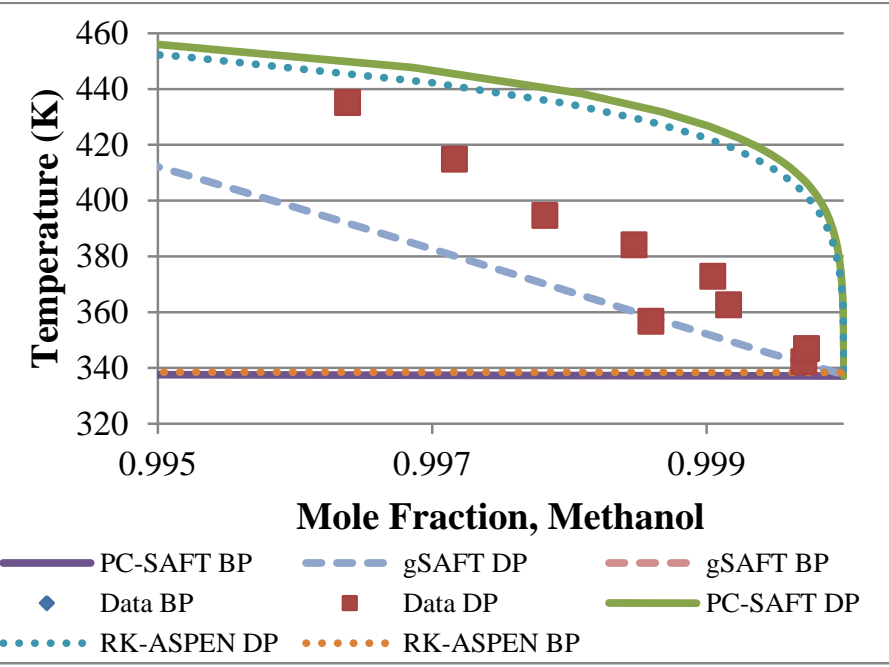

(b) Expanded vapor region

Figure 5. Methanol and methyl-oleate VLE at 1 atm (see color e-copy to distinguish curves)

\subsection{Binary LLE Mixtures}

Figures 9-13 display liquid-liquid equilibria for the six species in the biodiesel system. In Section 5.3, all of the data, except for methanol and methyl-oleate, were obtained from the NIST databank or the literature, with numerous datasets for each binary pair. All of the LLE data, except for methyl-oleate and water, were measured by the authors (see Appendix A). Error bars are provided in Figures 9-12 with their width being equal to 1 standard deviation on each side. While a dataset for triolein and methanol existed, it was of questionable accuracy [66]. Overall, as anticipated, the EoSs were less effective in modeling LLE than VLE data. 


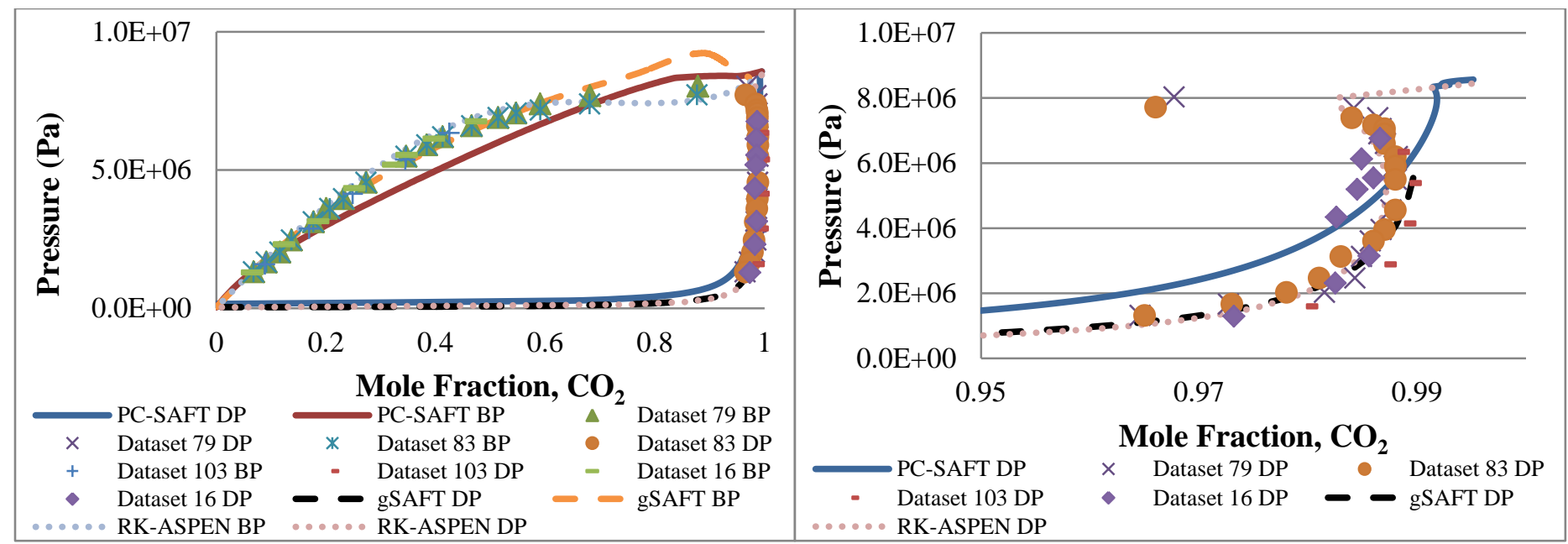

(a) At $313.14 \mathrm{~K}$ (full-scale)

(b) At $313.14 \mathrm{~K}$ (expanded vapor region)

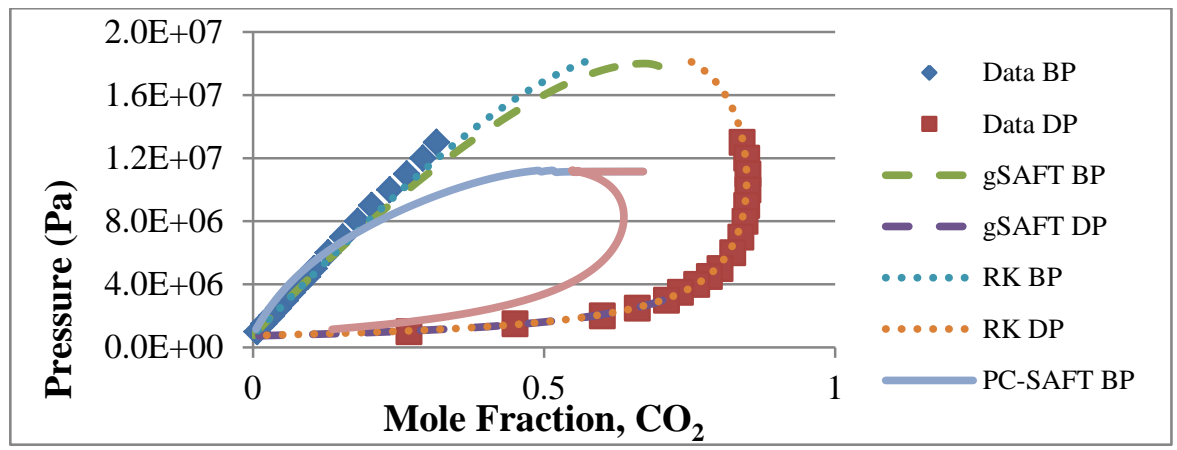

(c) At $398.06 \mathrm{~K}$

Figure 6. Methanol and $\mathrm{CO}_{2}$ VLE (see color e-copy to distinguish curves)

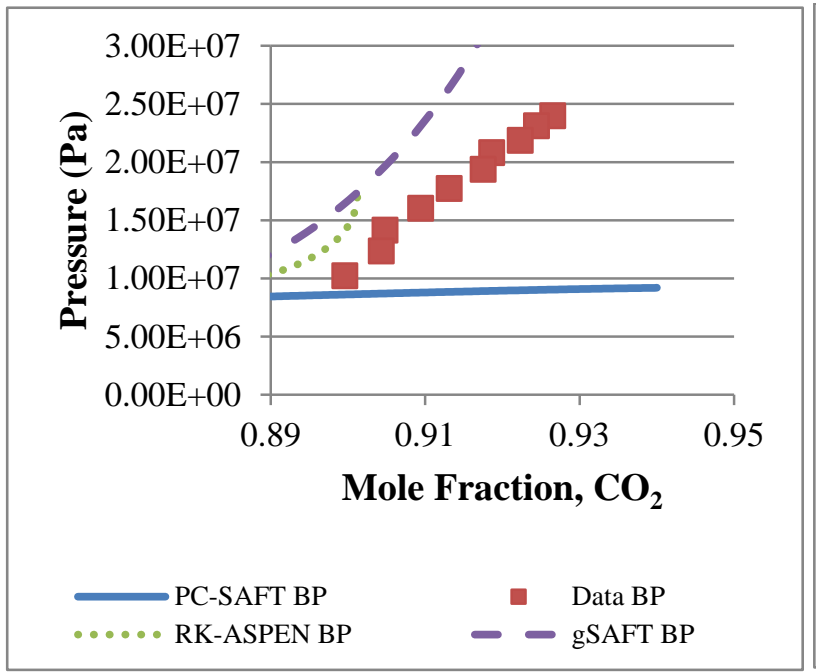

(a) At $313 \mathrm{~K}$ (bubble-point curve)

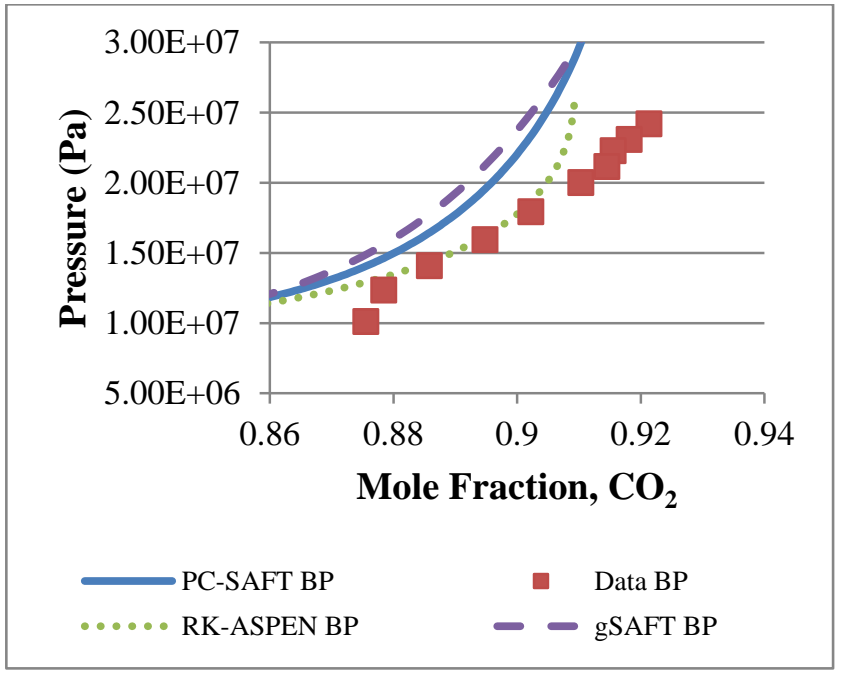

(b) At $333 \mathrm{~K}$ (bubble-point curve)

Figure 7. Triolein and $\mathrm{CO}_{2}$ VLE (see color e-copy to distinguish curves) 


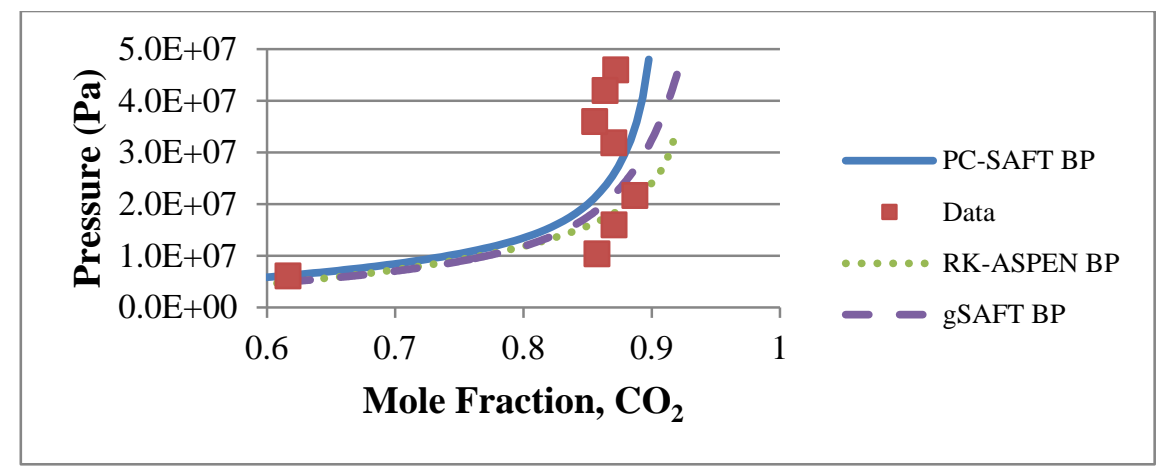

(c) At $363 \mathrm{~K}$ (bubble-point curve)

Figure 7. Triolein and $\mathrm{CO}_{2}$ VLE (see color e-copy to distinguish curves) (Cont'd.)

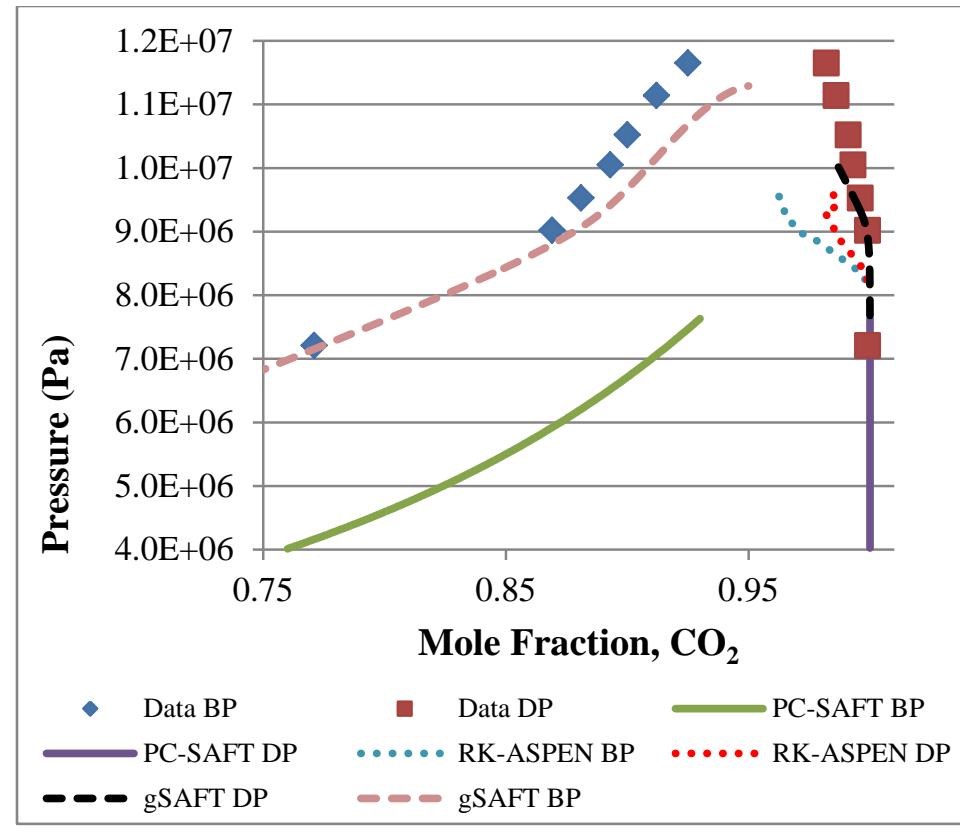

(a) At $313 \mathrm{~K}$

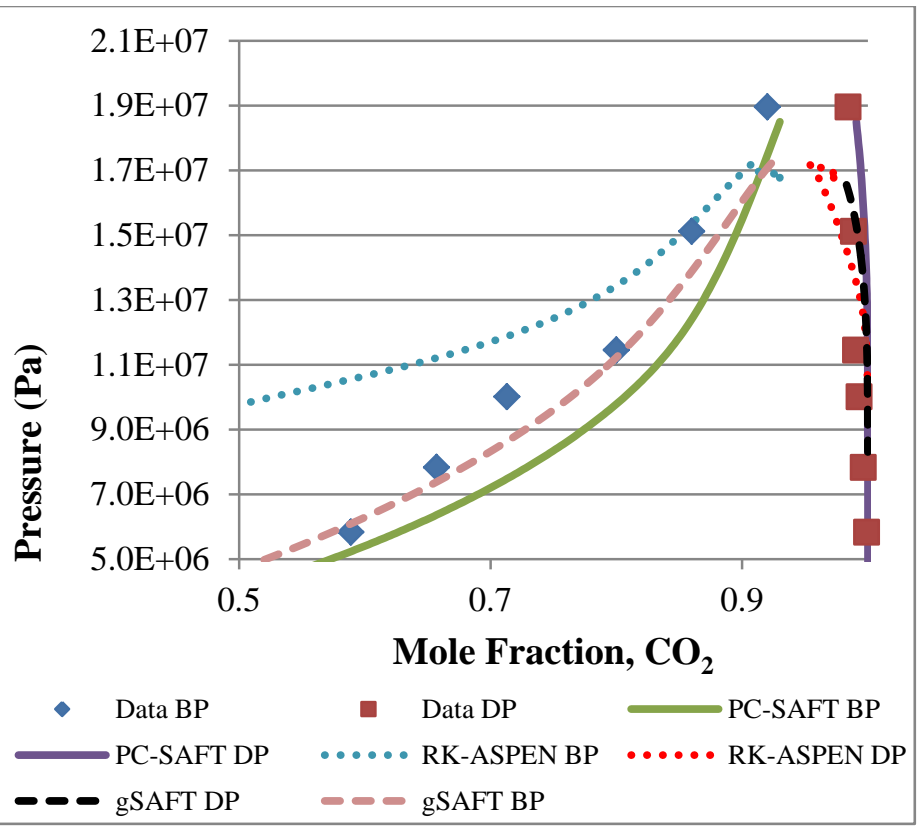

(b) At $333 \mathrm{~K}$

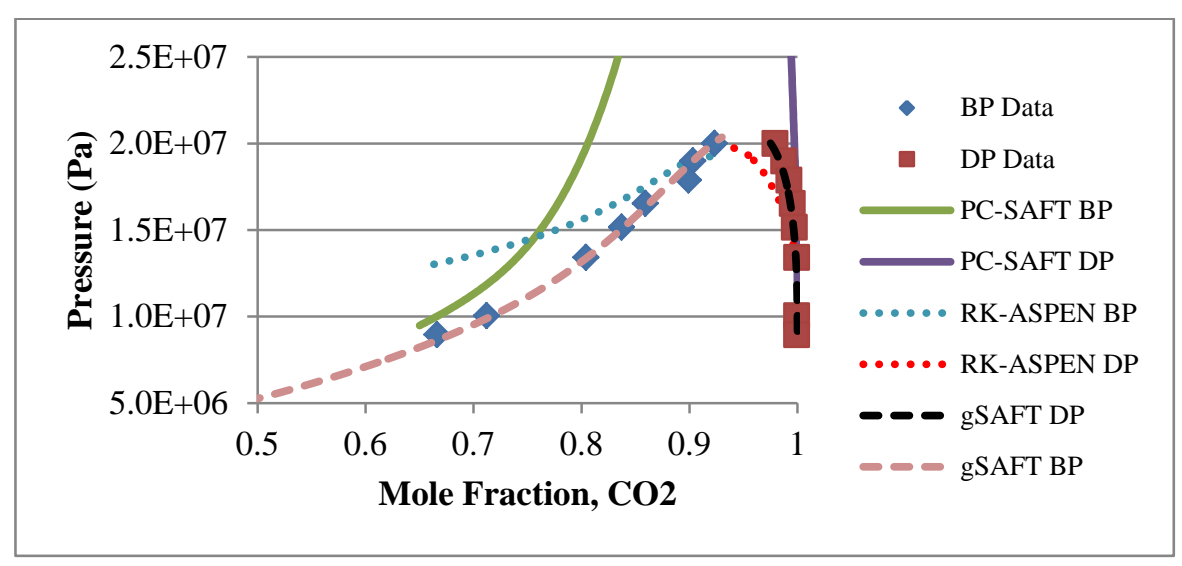

(c) At $343 \mathrm{~K}$

Figure 8. Methyl-oleate and $\mathrm{CO}_{2} \mathrm{VLE}$ (see color e-copy to distinguish curves) 
For methyl-oleate and water (Figure 13), the two available datasets differed by an order of magnitude [13,67]. The former is displayed because all three EoSs provided reasonable agreement. However, there were only three datapoints, and the EoS estimates did not fully agree with the data. Thus, these methyl-oleate and water LLE systems should be investigated more thoroughly in future studies.

Reasonable agreement with the triolein and water LLE data (Figure 10) were obtained by both SAFT equations. RK-ASPEN failed to yield LLE predictions at these conditions. Similarly, in Figure 9, both SAFT equations provide much better agreement with the trioleinmethanol LLE data.

The systems involving glycerol (Figures 11 and 12) were the most challenging to sample. It was difficult to determine when the phases had reached their equilibrium separation. As a result, the datasets exhibited large standard deviations for some points. Measurements for triolein in the glycerol bulk phase were particularly difficult, leading to only one useable datapoint at many temperatures. Note that although the error bars appear small in Figures 11 and 12, the x-axes (concentrations) are on a log-scale. See Appendix A for tabulated data. For these glycerol systems, PC-SAFT provides the best agreement with the data (as with the other LLE data), but surprisingly, all three EoSs (without binary interaction parameters) provide better estimates for the apolar bulk phases (a in both Figures 11 and 12). It was not possible to confirm this observation for the triolein - methanol or triolein-water systems (Figures 9 and 10) as the apolar phase could not be sampled.

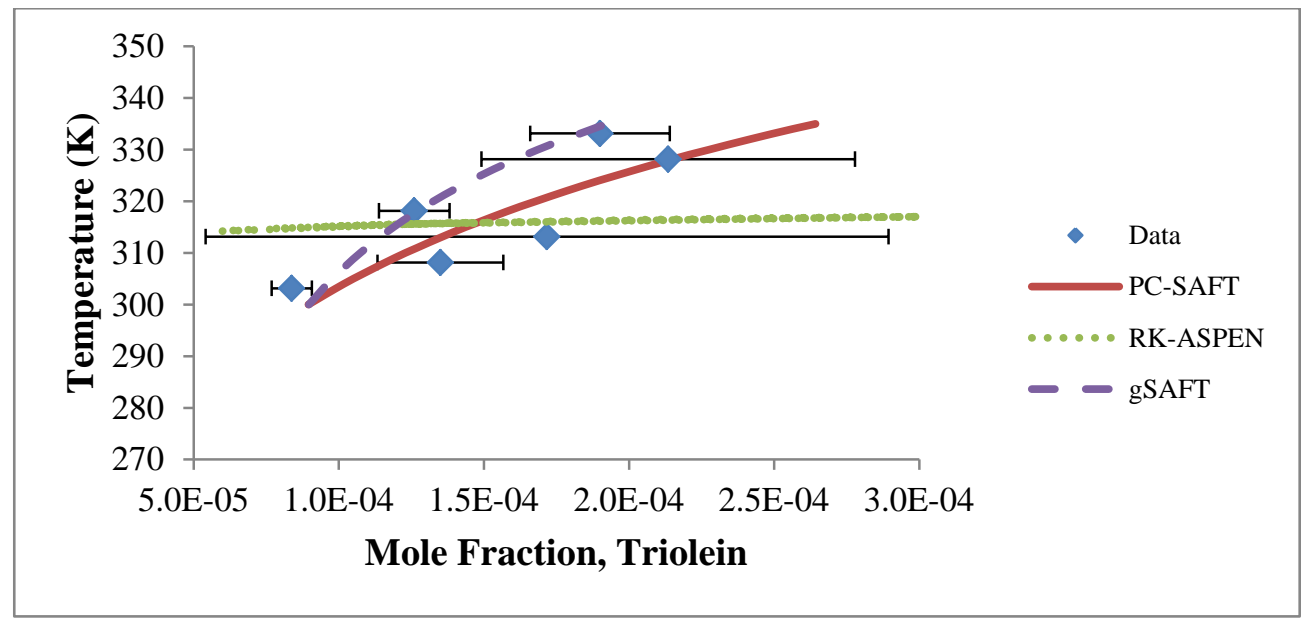

Figure 9. Triolein in the methanol phase (LLE at $1 \mathrm{~atm}$ ) 


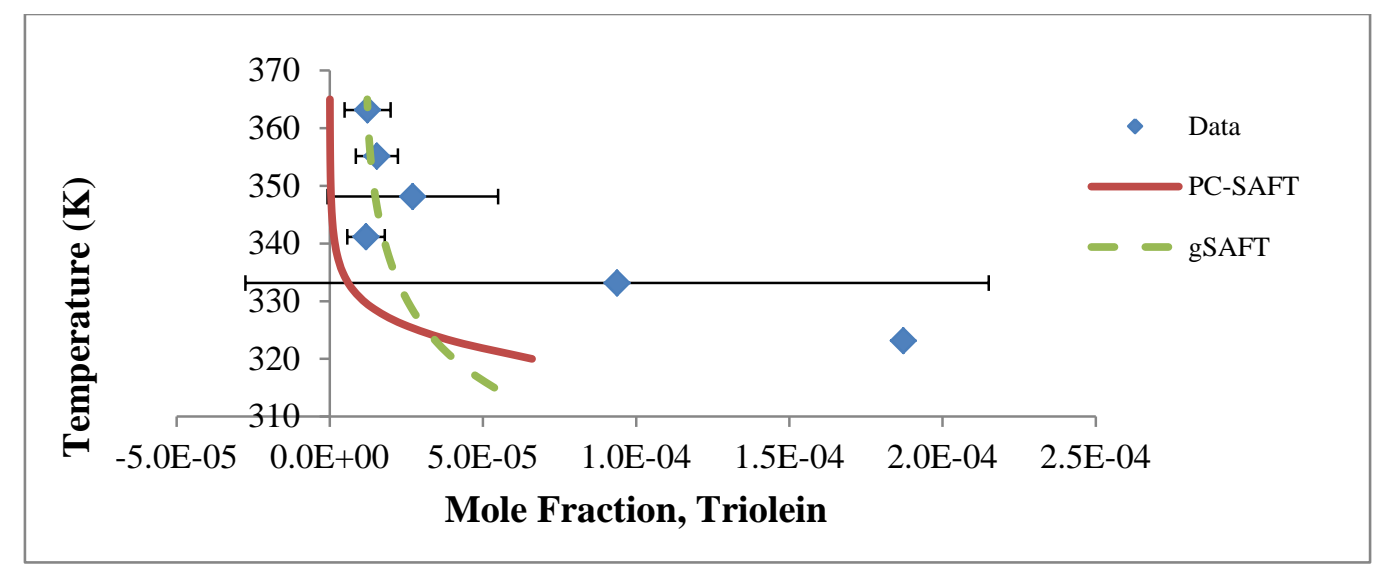

Figure 10. Triolein in the water phase (LLE at $1 \mathrm{~atm}$ )

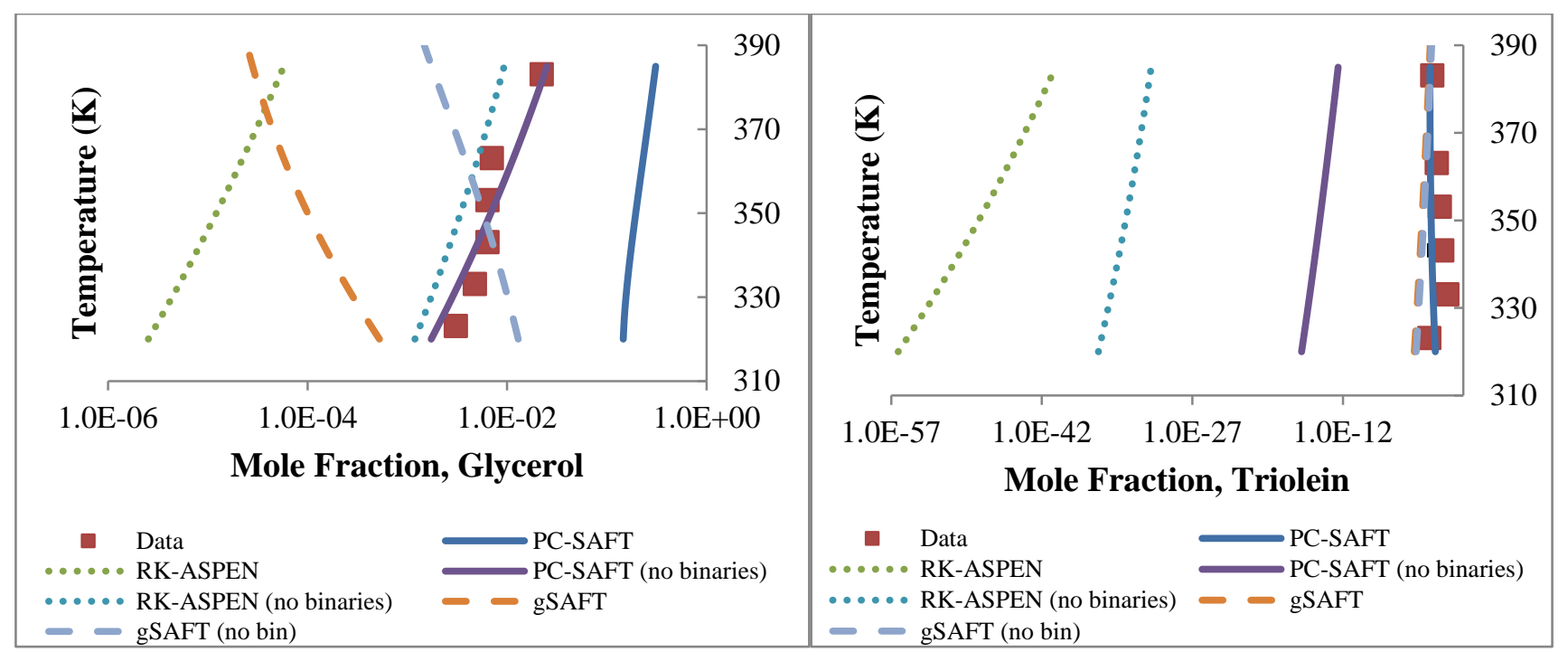

(a) Glycerol in the triolein phase

(b) Triolein in the glycerol phase

Figure 11. Glycerol and triolein LLE at $1 \mathrm{~atm}$. (note that the two gSAFT curves overlap in (b), and it is difficult to distinguish them - see color e-copy to distinguish curves)

\subsection{Ternary LLE Mixtures}

LLE data and model predictions for water, methanol, and methyl-oleate at $318.2 \mathrm{~K}$ and 1 atm are shown in Figure 14. For RK-ASPEN, significant deviations occur at high water concentrations in the aqueous phase, because RK-ASPEN doesn't accurately represent strongly associating mixtures. Good agreement is obtained by both SAFT EoSs, especially for regions of high water concentrations. PC-SAFT slightly under-predicts the solubility of methanol and 
methyl-oleate at high concentrations of both, while gSAFT over-predicts their solubility. However, the latter does a much better job of predicting the shape of the phase boundary curve.

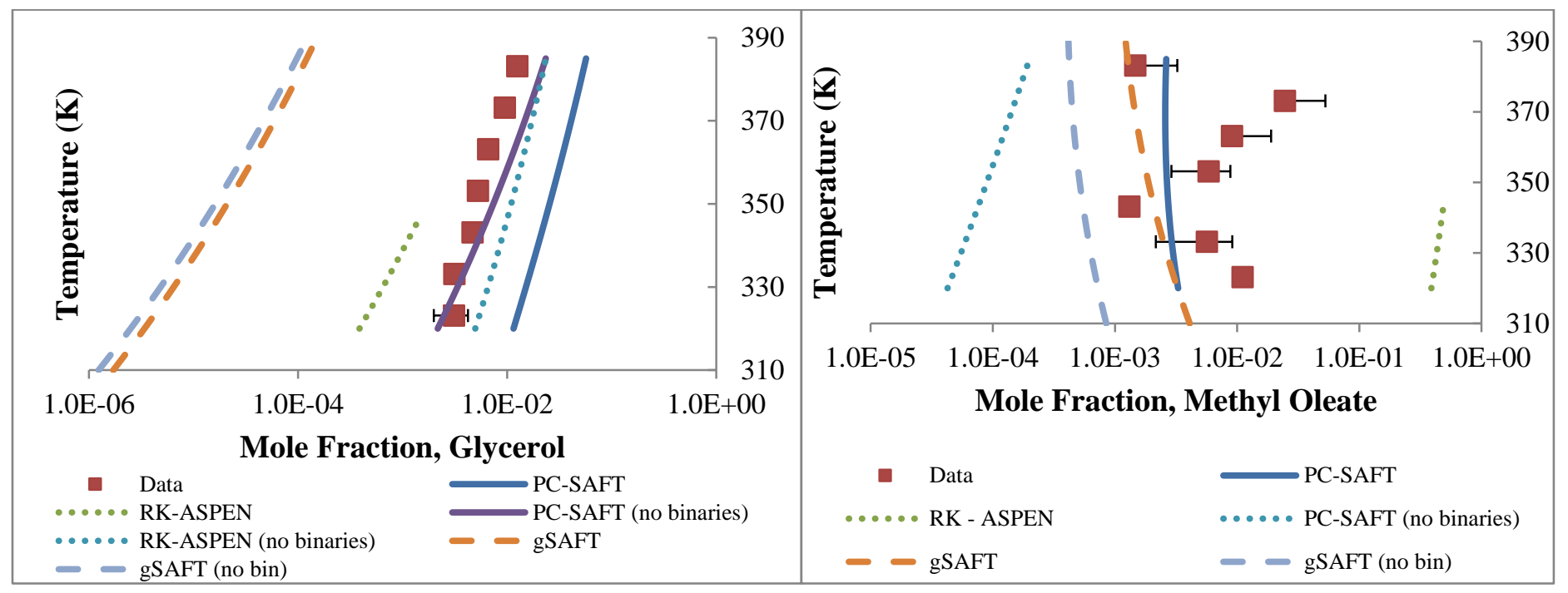

(a) Glycerol in the methyl-oleate phase

(b) Methyl-oleate in the glycerol phase

Figure 12. Glycerol and methyl-oleate LLE at 1 atm (see color e-copy to distinguish curves).

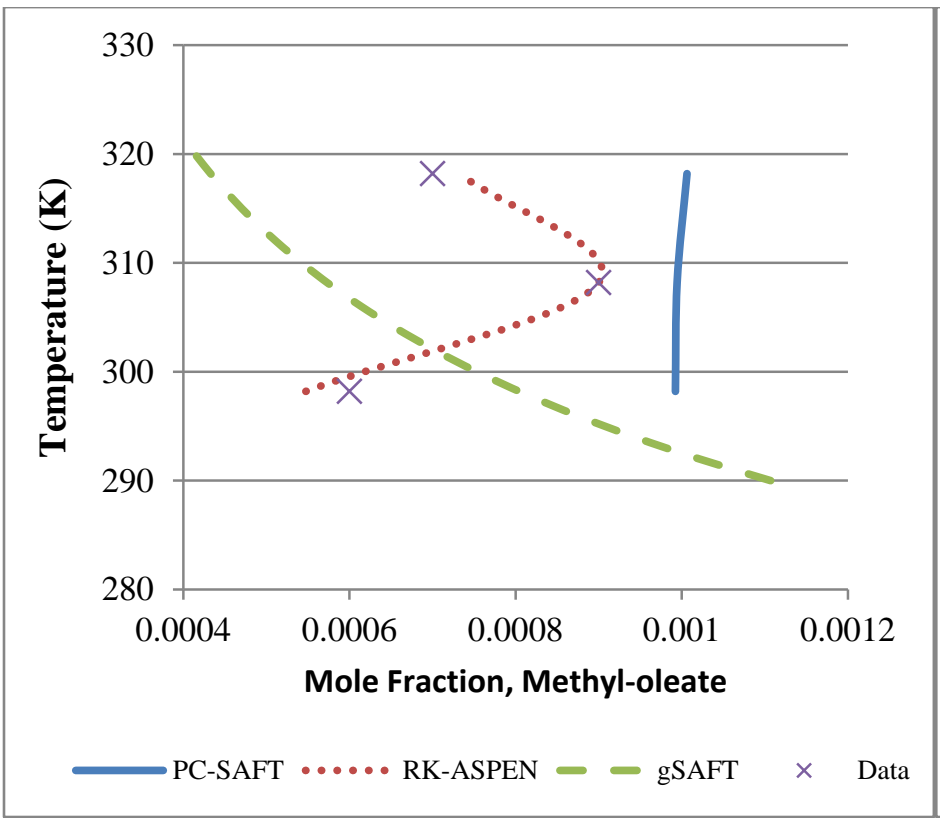

(a) Methyl-oleate in the water phase

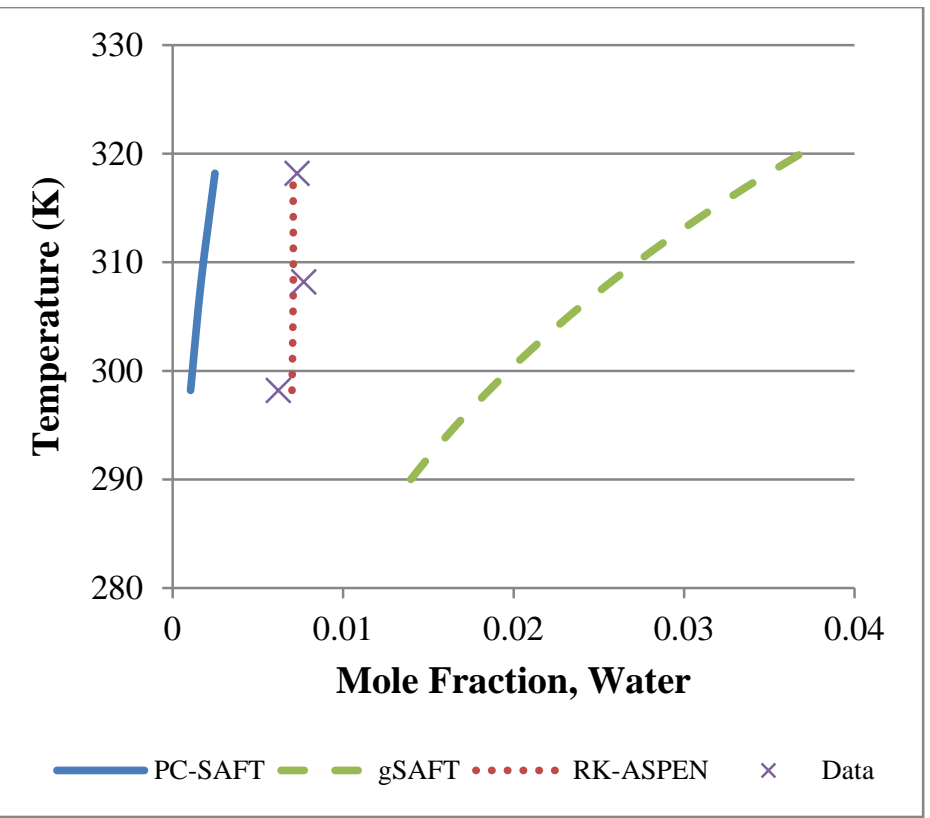

(b) Methyl-oleate in the water phase

Figure 13 Methyl-oleate and water LLE at 1 atm. 
For glycerol, methanol, and methyl-oleate at $333 \mathrm{~K}$ and $1 \mathrm{~atm}$ (Figure 15) poor agreement is achieved with RK-ASPEN, again because of its difficulty in representing associating systems. Good agreement is achieved with PC-SAFT, but not with gSAFT. The poor predictions shown for gSAFT could be due to either over-regression of parameters, because glycerol has two different associating sites (primary and secondary alcohol groups), for which separate parameters were regressed - as opposed to PC-SAFT, where the two standard associating parameters were regressed for the entire molecule. The inaccuracy shown for gSAFT could also result from the fact that methyl-oleate was represented using an assembly of groups, instead of unique parameters for the complete molecule, as was done for PC-SAFT. Between these two explanations, the first is more likely, as it explains the disparity in performance by gSAFT between Figures 14 and 15 - suggesting future attempts use fewer parameters. Note that the PCSAFT binary interaction parameters for glycerol and methyl-oleate were not used because they detract from the model performance when the glycerol, methyl-oleate, and methanol are present $[63,67]$.

These two ternary mixtures are typical of the effluent streams from the biodiesel reactor. Clearly, PC-SAFT should yield the best predictions for liquid-liquid phase distributions in the reactor effluent and product separation and purification units of a biodiesel process. Although, in further investigations, the regression of group parameters in gSAFT needs to be examined more closely.

\subsection{Ternary Inlet Mixtures}

Figure 16 examines the phase distributions of triolein, methanol, and $\mathrm{CO}_{2}$ mixtures at various pressures and compositions typical of the inlet conditions for a biodiesel reactor using $\mathrm{CO}_{2}$ to increase conversion rates $[5,68]$. Only the triolein mole fraction is shown. The mole fractions of methanol and $\mathrm{CO}_{2}$ are based on the triolein mole fraction with the triolein:methanol molar ratio fixed at 1:4,032. As shown in the legend, each symbol represents a different phase distribution at equilibrium, where dashes $(\mathrm{V})$ represent a vapor (or supercritical) phase, triangles (L) a liquid (or supercritical) phase, stars (VLE) vapor and liquid phases at equilibrium, diamonds (LLE) two liquid phases at equilibrium, and circles (VLLE) vapor-liquid-liquid equilibria. Open spaces arise when the Gibbs flash method in ASPEN PLUS (see footnote 1) algorithm did not converge. Note that a supercritical phase can be classified as either a vapor or 
liquid by the equilibrium algorithm, and therefore, for example, the transition from vapor to liquid at elevated pressures in Figure 16 (c and d) is not physically realistic.
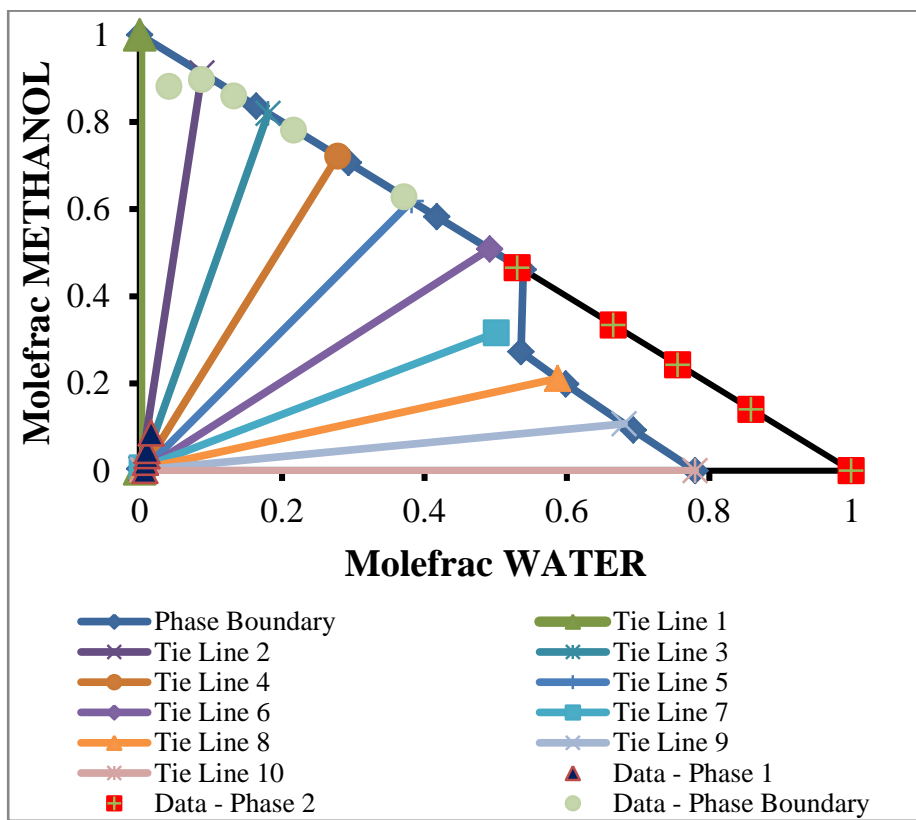

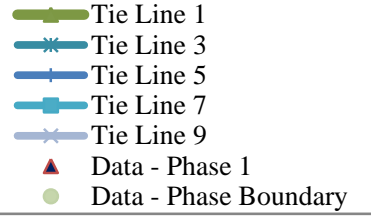

(a) Predicted with RK-ASPEN

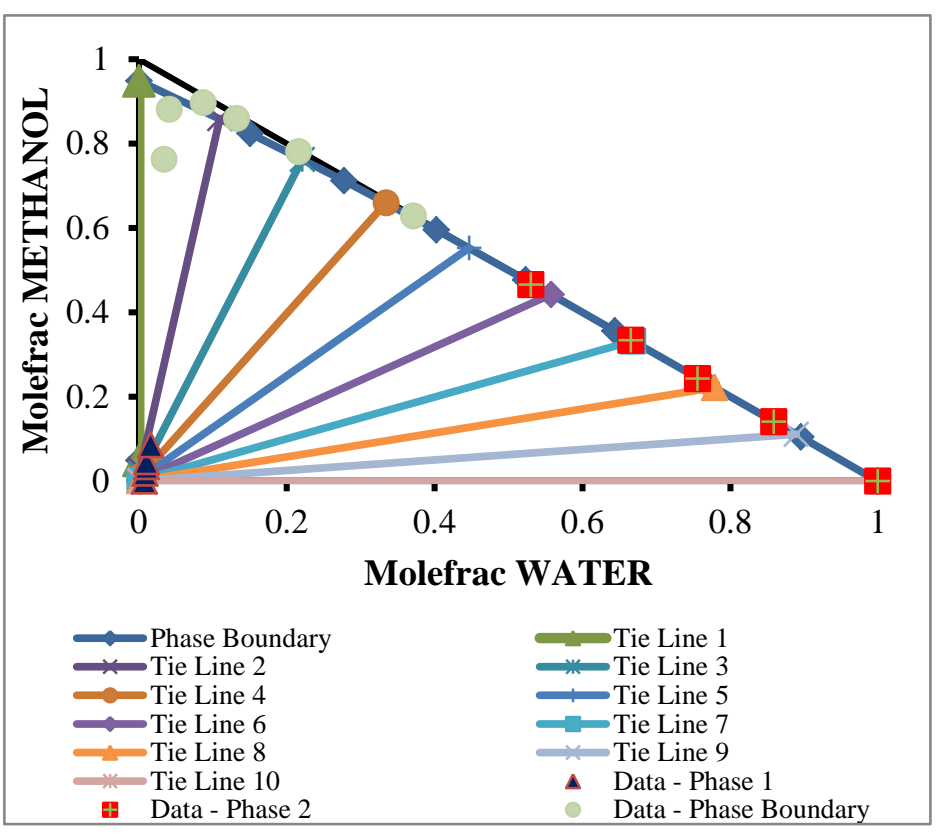

(b) Predicted with PC-SAFT

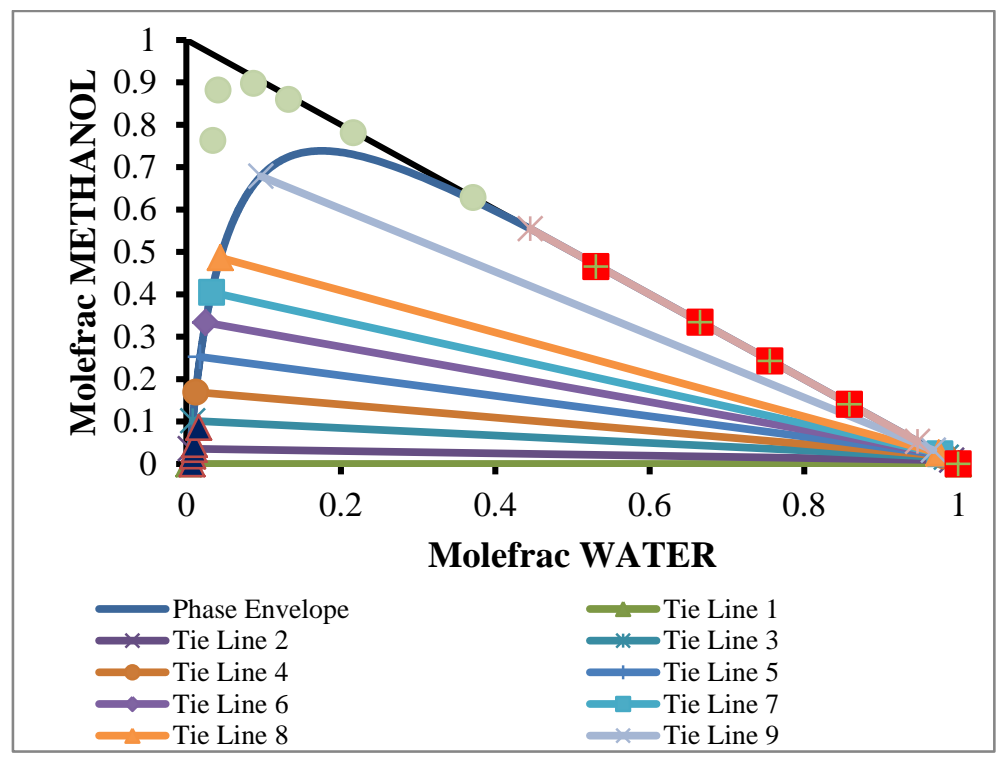

(c) Predicted with SAFT- $\gamma$ Mie (gSAFT)

Figure 14. LLE for water, methanol, and methyl-oleate at $318.2 \mathrm{~K}$ and $1 \mathrm{~atm}$ (see color e-copy images to distinguish the data and curves). 

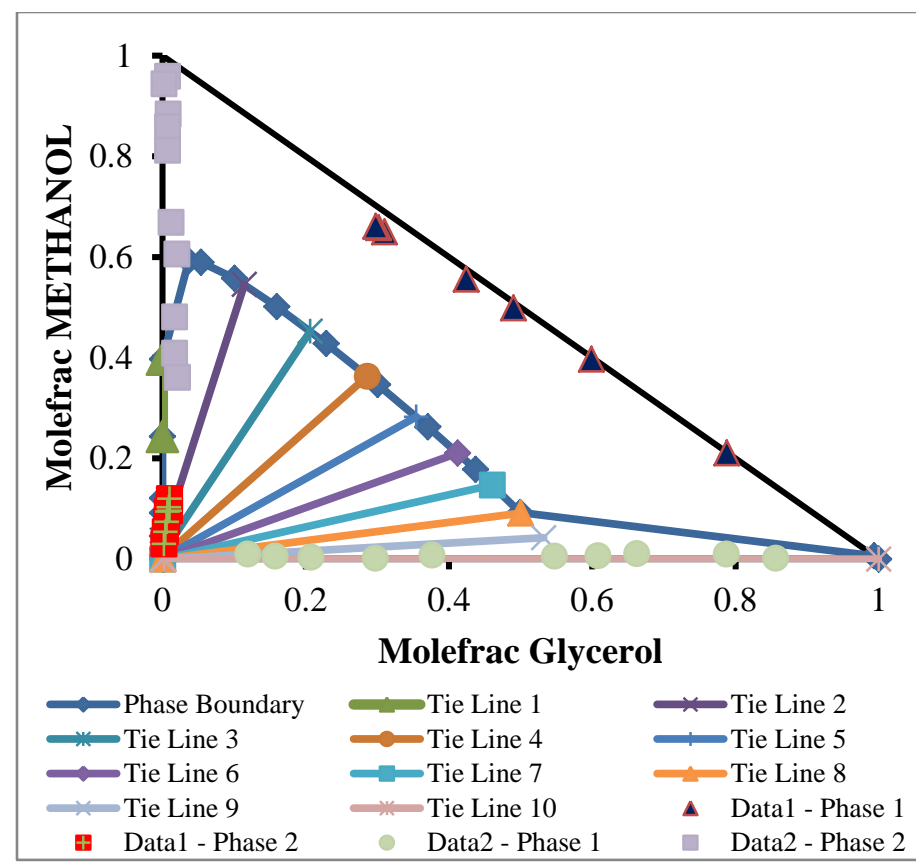

(a) Predicted with RK-ASPEN

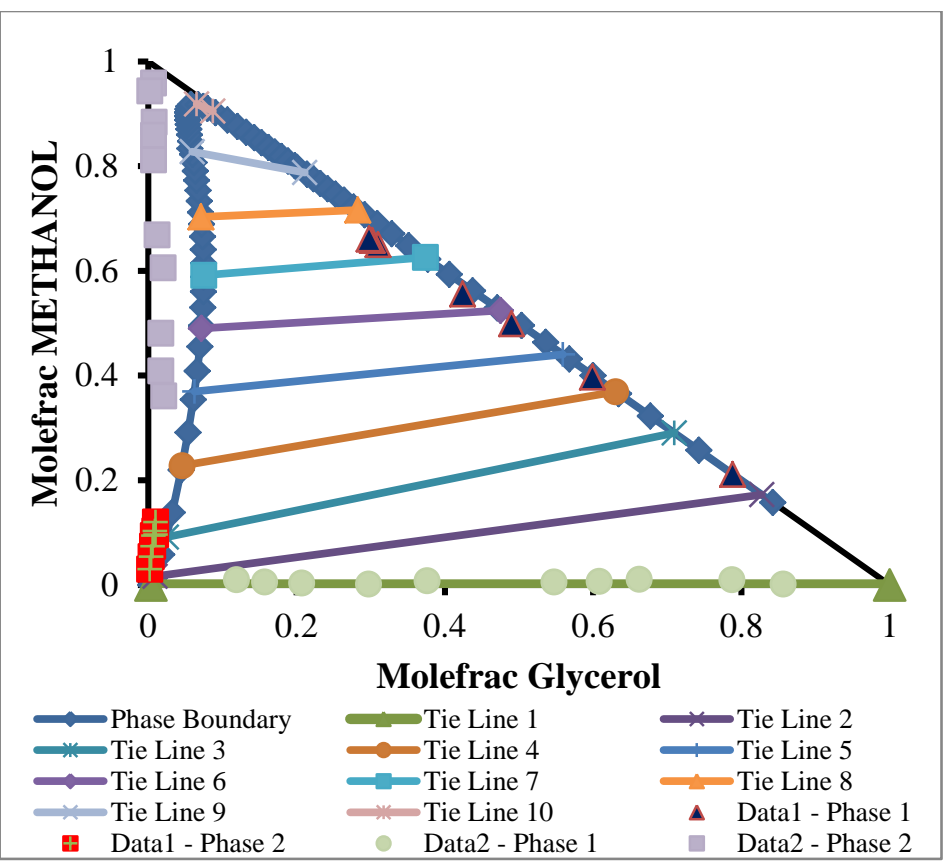

(b) Predicted with PC-SAFT

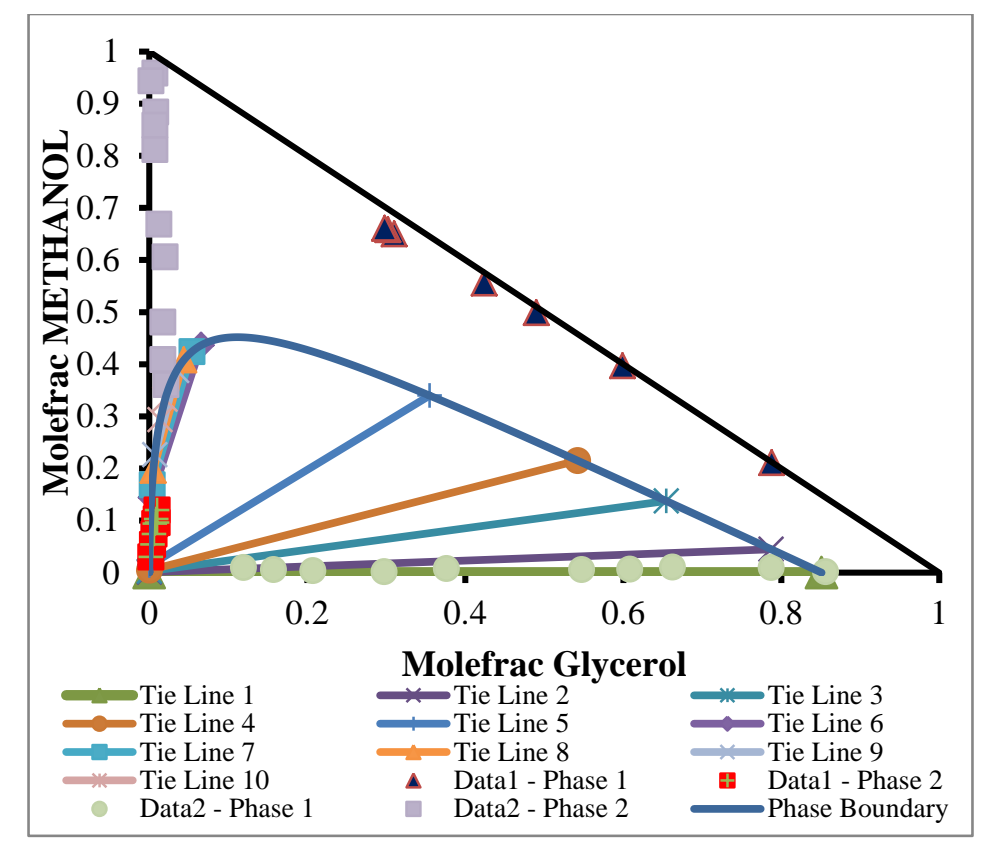

(c) Predicted with SAFT- $\gamma$ Mie (gSAFT)

Figure 15. LLE for glycerol, methanol, and methyl-oleate at $333 \mathrm{~K}$ and $1 \mathrm{~atm}$ (see color e-copy images to distinguish the data and curves). 
The lines, which represent approximate phase boundaries, connect experimental phase transition datapoints [5]; that is, orange circles (showing a transition from supercritical phase to VLE) and purple crosses (showing a transition from VLE to VLLE). Unfortunately, as can be seen in the five sub-figures, none of the EoSs accurately predict all three of these regions.

RK-ASPEN with no binary interaction parameters (Figure 16(a)) is most effective in predicting the VLLE region, but the Gibbs flash method fails to converge in much of the VLE or supercritical regions. RK-ASPEN with binary interaction parameters (Figure 16(b)) is more robust in terms of convergence, and correctly represents most of the supercritical region and the VLE region, but fails to predict any VLLE behavior.

gSAFT (Figure 16(e)) predicts the supercritical region and the VLE region, as well as their transition, almost perfectly. However, like RK-ASPEN with binary interaction parameters, it fails to predict any VLLE behavior, because it does not predict a liquid-liquid split between methanol and triolein at these conditions (as opposed to those in Figure 9). The poor predictions in the VLLE region are likely due to two factors: (1) the weighting factors for the liquid density [200] and vapor pressure [1] used during the regressions herein (Section 4) were not applied to groups that had been regressed in prior studies $\left(\mathrm{CH}_{3}\right.$ and $\mathrm{CH}_{2}$, which are crucial for triolein and methyl-oleate property estimation); (2) the group contribution method is not as accurate as regressing parameters for individual molecules. Thus future studies should regress "groups" that are equivalent to triolein and methyl-oleate, and ranges of weighting factors should be adjusted to compare the estimates of PC-SAFT and gSAFT. If gSAFT were shown to be more accurate using "molecular" groups, which is likely given the binary systems diagrams in Sections 5.2 and 5.3, the molecules could be dissected into various groups, with the objective of increasing flexibility without significantly decreasing accuracy.

PC-SAFT with no binary interaction parameters (Figure 16(c)) accurately predicts the supercritical region and much of the VLLE region, but fails to predict any part of the VLE region. PC-SAFT with binary interaction parameters clearly improves predictions in the VLE region, but only at low triolein mole fractions, as shown in Figure 16(d). The supercritical region is predicted as a liquid phase, and the transition from VLE to VLLE is predicted properly - but VLE is predicted in a significant portion of the VLLE region. After adjusting convergence tolerances and flash algorithms, but obtaining the same incorrect phase distributions, phase stability checks were implemented for PC-SAFT with binary interaction parameters 
To check phase stability, the tangent-plane-distance criteria [42, 43], as discussed in Section 2, was implemented, using the FORTRAN code provided by Prof. Romain Privat (Webpage: Prof. Romain Privat's Homepage). When using PC-SAFT with binary interaction parameters (Figure 16(d)), the Privat code showed that the liquid phase in the VLE predictions (in the intermediate portion of the VLLE region) is unstable, as shown in the lower enclosed region of Figure 17. Similarly, it showed that the liquid phases predicted for high triolein concentrations in the VLE region are unstable. Note, however, that negative tangent-plane distances were observed at higher triolein mole fractions in the supercritical region, indicating that a second phase at equilibrium is incorrectly predicted by PC-SAFT with interaction parameters.

Additional code was not written to reinitialize the flash calculations with improved guesses for the phases at equilibrium - primarily because the effect of the phase distribution on the rate of the transesterification reaction(s) in the VLLE region is demonstrated sufficiently well, next in Section 6. However, improvements in the ASPEN PLUS flash algorithms (RGIBBS and FLASH3) in the critical region would allow higher fidelity EoSs (like PC-SAFT) to be used more effectively for these mixtures - thus yielding more accurate predictions for reactor conversions.

Note that phase stability was not examined for gSAFT - as Process Systems Enterprise (PSE), creator of gSAFT, performs tangent-plane distance phase-stability checks.

\section{Kinetics and Reactor Design}

For the transesterification reaction involving triolein, methanol, and $\mathrm{CO}_{2}$, overall composition data were measured dynamically at various catalyst loadings, using a Nafion solidacid catalyst in both bead and powder form at $95^{\circ} \mathrm{C}$ and $9.65 \mathrm{MPa}$ [68]. These data include triolein, diolein, monoolein, and methyl-oleate concentrations. Glycerol, methanol, and $\mathrm{CO}_{2}$ concentrations at each time were calculated using initial substrate loadings and mole balances. Because phase equilibrium data involving diolein and monoolein were unavailable, the simplified reaction:

$$
T G_{\text {branch }}+\text { methanol } \underset{\begin{array}{c}
\text { solid-acid catalyst } \\
\text { carbon dioxide }
\end{array}}{\stackrel{m}{\rightleftarrows} \text { thyl oleate }}+\frac{1}{3} \text { glycerol }
$$




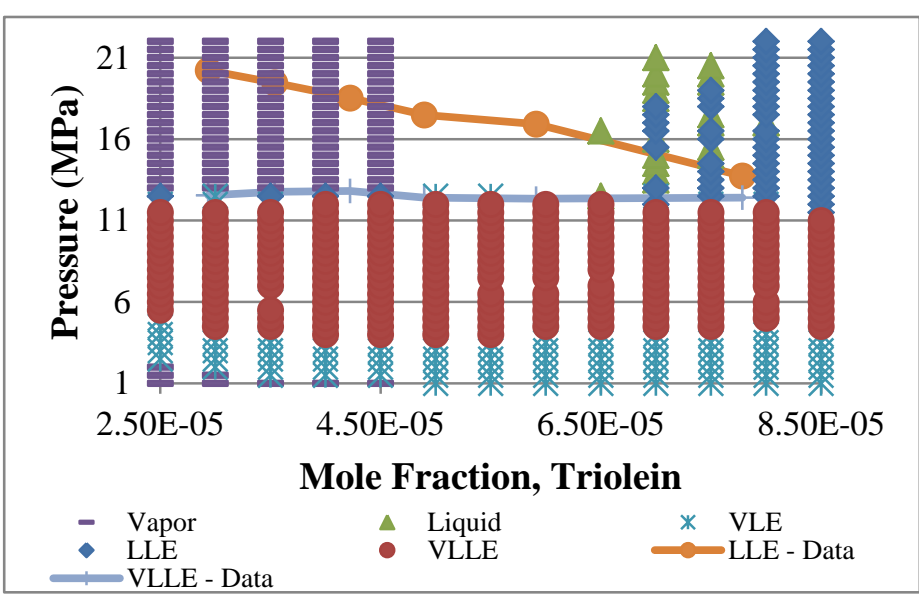

(a) RK-ASPEN (no binary interaction parameters)

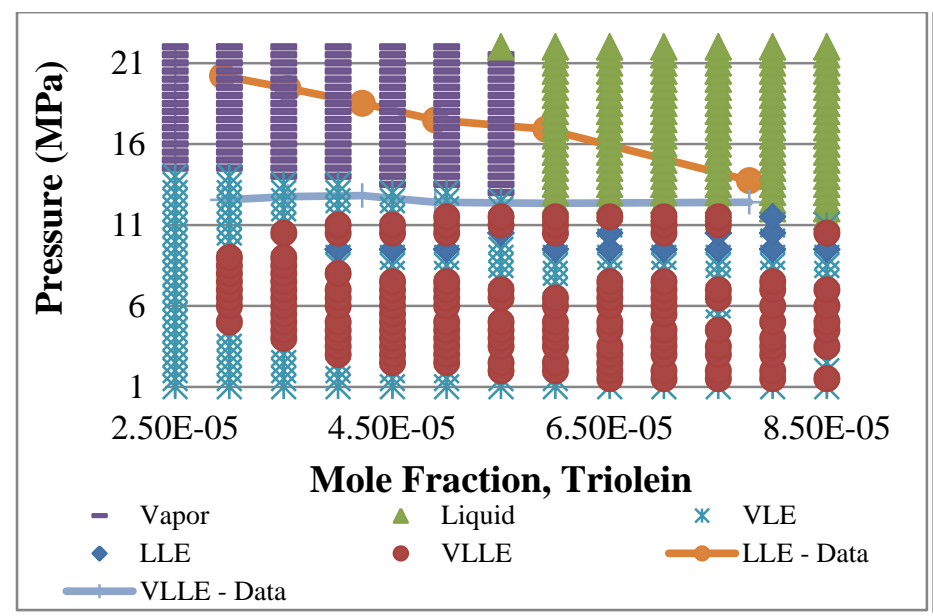

(c) PC-SAFT (no binary interaction parameters)

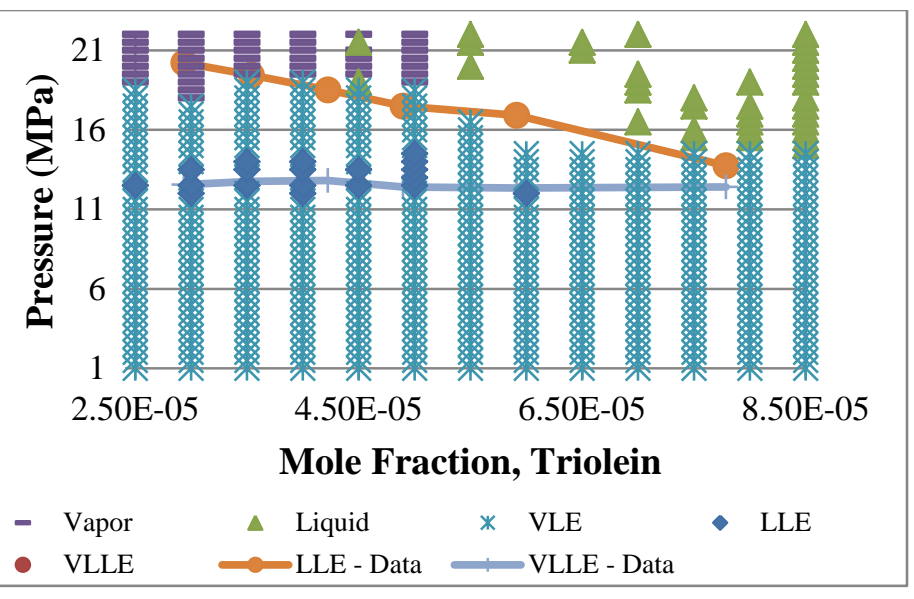

(b) RK-ASPEN (with binary interaction parameters)

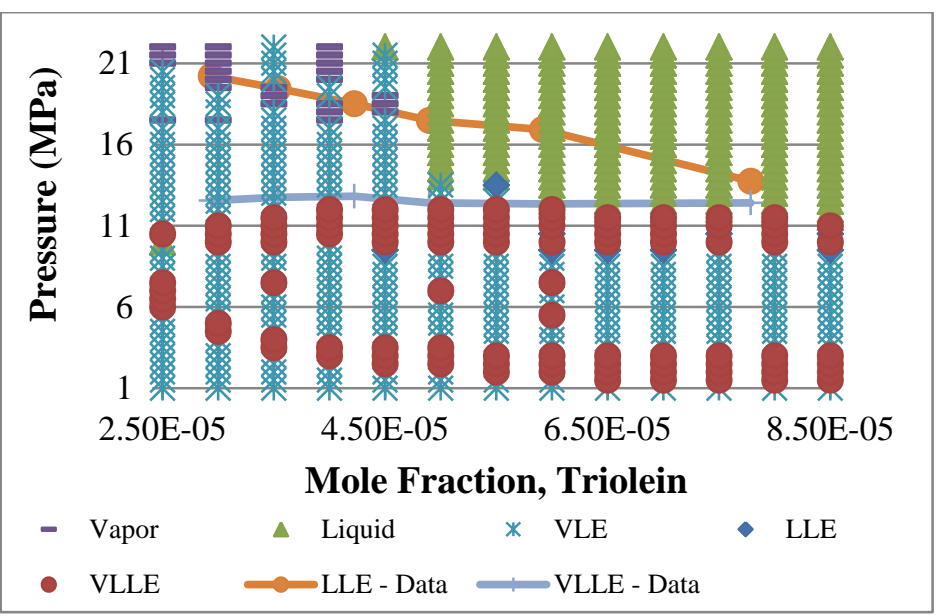

(d) PC-SAFT (with binary interaction parameters)

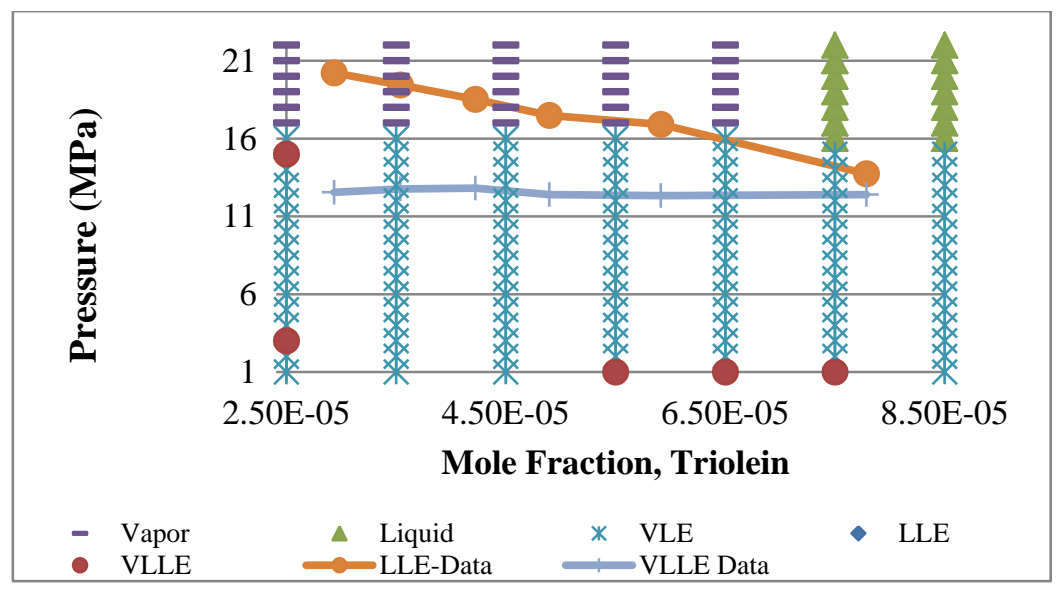

(e) SAFT- $\gamma$ Mie (gSAFT)

Figure 16. Triolein, methanol, and $\mathrm{CO}_{2}$ phase equilibria at $353.15 \mathrm{~K}$. 


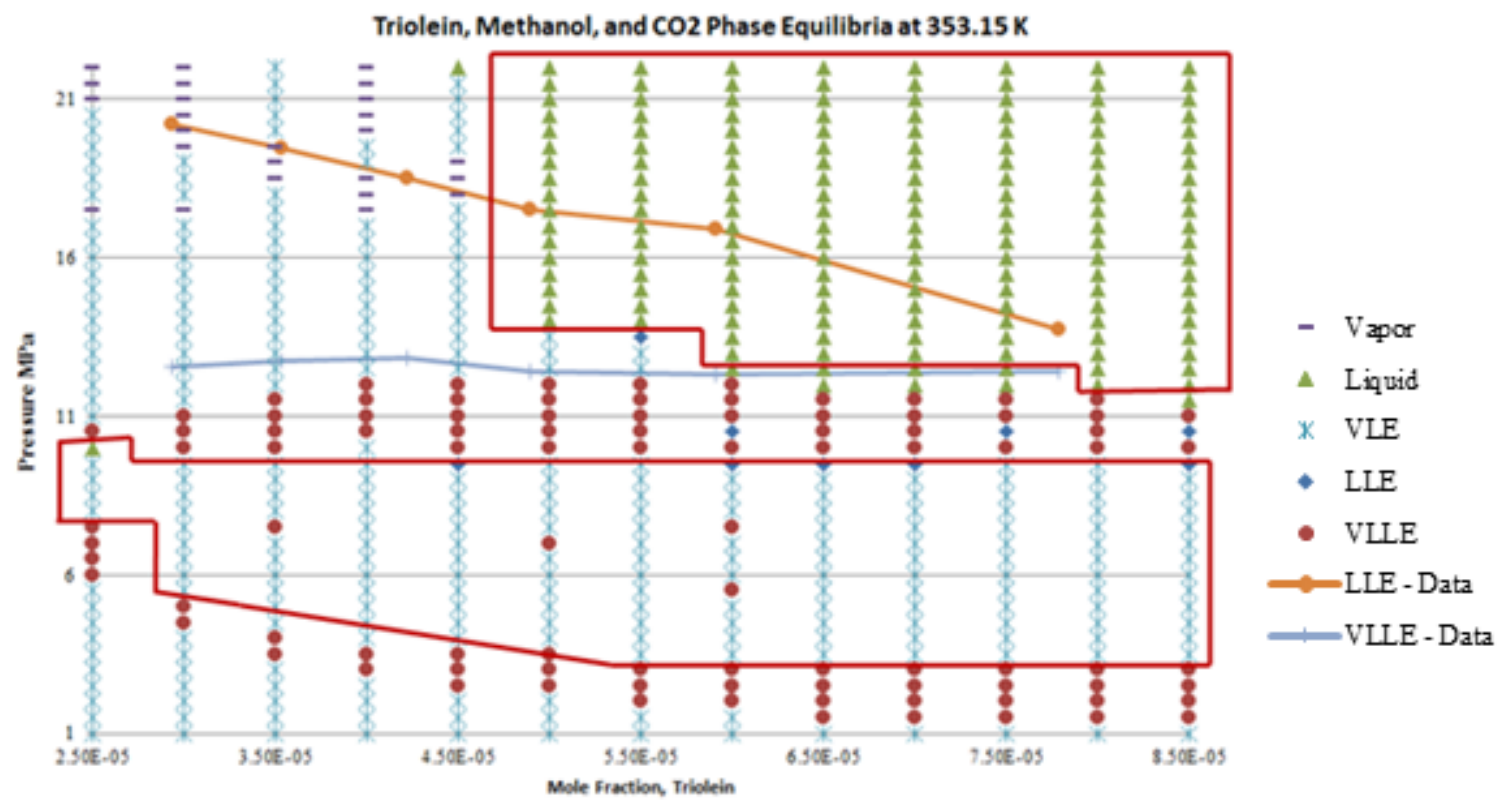

Figure 17. Tangent-plane-distance regions of stability and instability (PC-SAFT with binary parameters at $353.15 \mathrm{~K}$ ). The unstable regions are enclosed in two polygons.

was used in place of the kinetic mechanism in Figure 1. The mechanism is formulated in terms

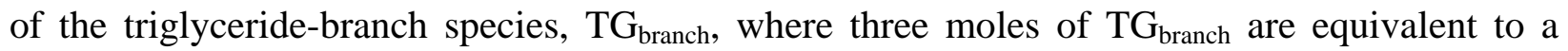
mole of triolein, two moles of $\mathrm{TG}_{\text {branch }}$ and one-third of a mole of glycerol is equivalent to a mole of diolein, and one mole of $\mathrm{TG}_{\text {branch }}$ and two-thirds of a mole of glycerol is equivalent to a mole of monoolein.

This reaction mechanism was translated into the intrinsic reaction-rate:

$r x n=k_{f}[c a t]^{n_{f}}\left[\right.$ TG $\left.G_{\text {branch }}\right][$ methanol $]-k_{r}[\text { cat }]^{n_{r e v}}[$ methyl_oleate $][\text { glycerol }]^{\frac{1}{3}}$

with the ODE mass balances:

$$
\frac{d\left[C_{i}\right]}{d t}=v_{R 1, i} * r x n
$$

where $k_{\mathrm{f}}$ is the forward rate constant, $k_{\mathrm{r}}$ is the reverse rate constant, [cat] is the catalyst concentration, $n_{\mathrm{f}}$ is the exponent of the catalyst concentration in the forward direction, $n_{\mathrm{rev}}$ is the exponent of the catalyst concentration in the reverse direction, $\left[C_{i}\right]$ is the concentration of species $i$, and $v_{\mathrm{R} 1, i}$ is the stoichiometric coefficient of species $i$ in reaction $\mathrm{R} 1$.

Initially, $k_{\mathrm{f}}, k_{\mathrm{r}}, n_{\mathrm{f}}$, and $n_{\mathrm{rev}}$ were regressed using the bulk concentrations in the experimental $50 \mathrm{~mL}$, agitated reactor vessel [68]. An explicit Euler integration was used in MS 
Excel with a time-step of 18 seconds. The sum-of-the-square differences between the concentration data and the integrated concentrations for triolein, methanol, and methyl-oleate (for the entire stirred tank) were incorporated into a relative, weighted least-squares objective function, which weighted the concentration differences more heavily as reaction time increased [1]. Note that triolein, methanol, and methyl-oleate concentrations were weighted equally. Also, glycerol concentrations were not included in the objective function because the calculated moles of glycerol were substantially larger than experimental values - with each mole of diolein replaced by two moles $\mathrm{TG}_{\text {branch }}$ and two-thirds mol glycerol and each mole of monoolein replaced by one mole $\mathrm{TG}_{\text {branch }}$ and one-third mol glycerol.

The minimization of the objective function yielded the kinetic constants in column 2 of Table 7. These constants served as initial guesses in a custom-written FORTRAN subroutine in ASPEN PLUS that incorporates the effect of the phase behavior on the reaction kinetics using the algorithm in Figure 18.

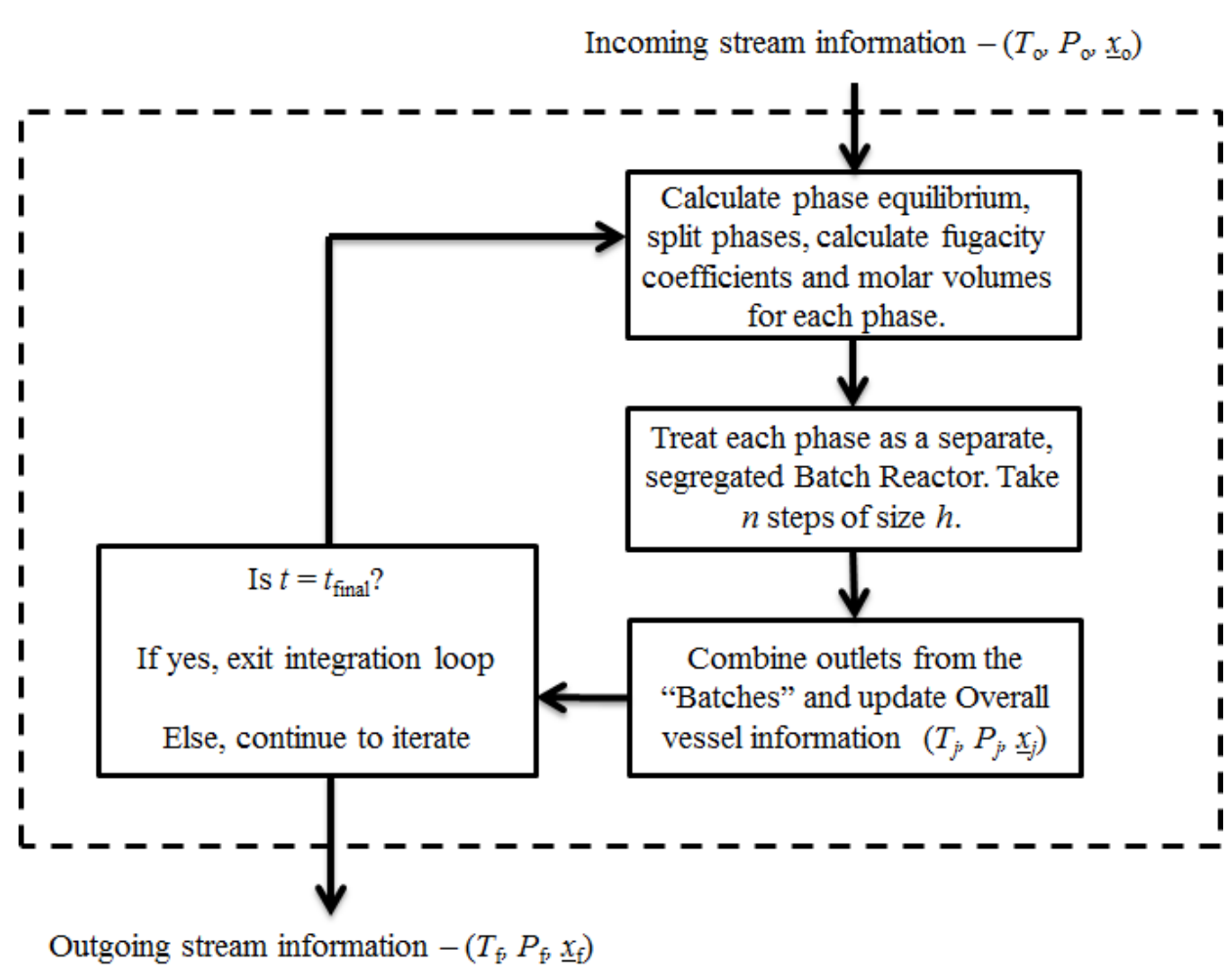

Figure 18. Multiphase-kinetic reactor algorithm created for ASPEN PLUS. 
As with the MS Excel model, experimental data for eight loadings, over a 4-hour reaction time, were used. The reaction temperature was maintained at $95^{\circ} \mathrm{C}$. The total vessel volume was the sum of the three "phase" batch reactors, and was calculated every 10 time-steps (18 seconds per time-step) along with the phase equilibria. The phase volumes remained nearly constant during the 4-hour reaction, with the vapor phase (methanol and $\mathrm{CO}_{2}$ ) taking about two-thirds of the vessel volume. The aqueous liquid (methanol and glycerol) accounted for most of the remaining third, with the apolar liquid (triolein, methyl oleate, with some methanol) never exceeding $0.25 \%$ of the total volume. The change in vessel volume throughout the reaction was less than $1 \%$, with no volume adjustments implemented.

Because RK-ASPEN with no binary interaction parameters (Figure 16a) is the only thermodynamics package to predict VLLE at the reactor conditions ( $95^{\circ} \mathrm{C}$ and $\left.9.65 \mathrm{MPa}\right)$, it was used to determine the four kinetic constants in column 3 of Table 7 - again using a relative, weighted least-squares regression. The concentration profiles for triolein, methanol, and methyl-oleate are shown in Figure 19, and the reaction rate profiles are shown in Figure 20. Note that the $\mathrm{CO}_{2}$ concentration profiles in each phase do not change appreciably. $\mathrm{CO}_{2}$ accounts for roughly $92.5 \mathrm{~mol} \%$ in the vapor phase, $61.7 \mathrm{~mol} \%$ in the apolar liquid phase, and $43.7 \mathrm{~mol} \%$ in the aqueous liquid phase. Overall, $63.3 \%$ of the total $\mathrm{CO}_{2}$ moles are in the vapor phase, $0.57 \%$ in the apolar liquid phase, and $36.11 \%$ in the aqueous liquid phase.

Table 7. Kinetic Parameters

\begin{tabular}{|c|c|c|c|}
\hline Constant & MS Excel & ASPEN PLUS & Units \\
\hline$k_{\mathrm{f}}$ & 0.063 & 0.104 & $\left(\mathrm{~m}^{3}\right)^{2} /\left(\mathrm{kmol}^{2} \mathrm{~s}\right)$ \\
\hline$k_{\mathrm{r}}$ & 0.006 & 0.114 & $\left(\mathrm{~m}^{3}\right)^{2} /\left(\mathrm{kmol}^{2} \mathrm{~s}\right)$ \\
\hline$n_{\mathrm{f}}$ & 1.253 & 1.269 & - \\
\hline$n_{\mathrm{rev}}$ & 0.700 & 0.700 & - \\
\hline
\end{tabular}

Liquid 1 is the triolein (apolar liquid) phase and liquid 2 is the aqueous phase. Note that methanol distributes between the two phases, due to $\mathrm{CO}_{2}$ increasing its solubility in the apolar phase. The forward reaction occurs almost exclusively in the apolar liquid phase. The vapor phase has a negligible reaction rate because of triolein's low vapor pressure. The reverse reaction occurs in the second liquid, because essentially all produced glycerol moves to the 
aqueous phase and there is negligible triolein present to drive the forward reaction. Note that the system is predicted to remain in the 3-phase region throughout the course of the reaction.

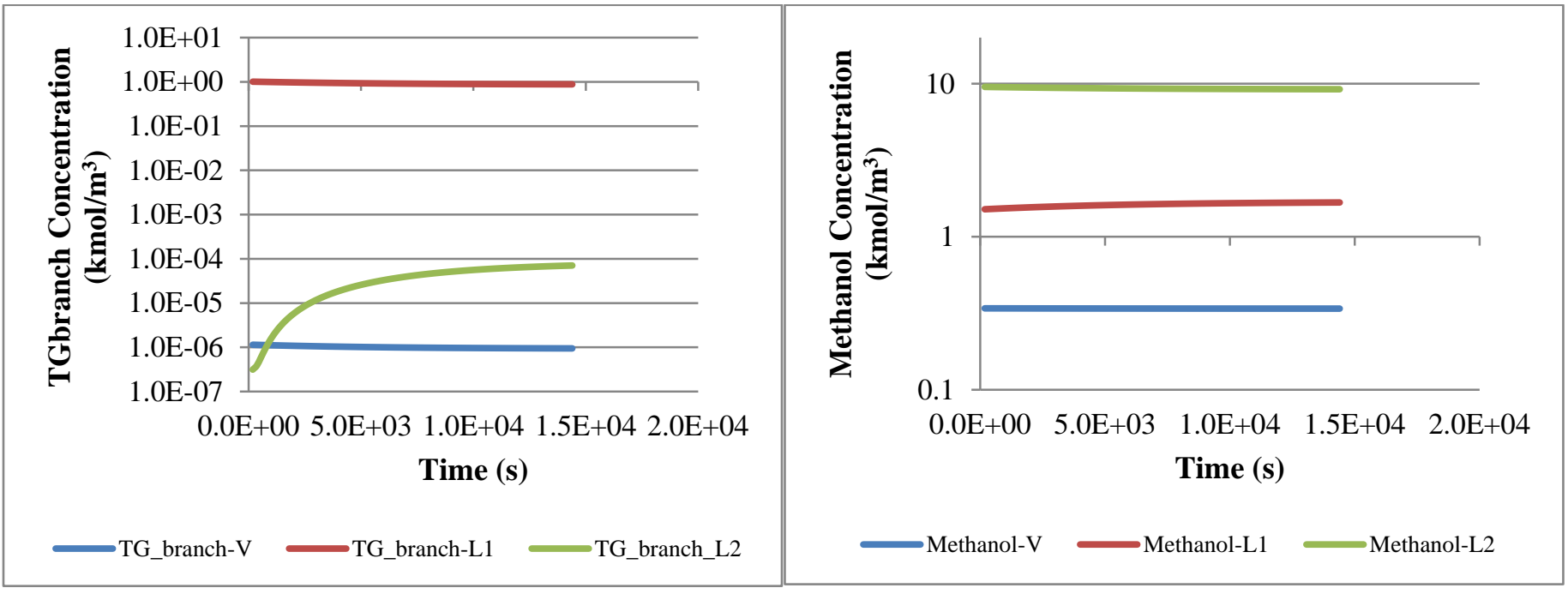

(a) $\mathrm{TG}_{\text {branch }}$ concentration profiles

(b) Methanol concentration profiles

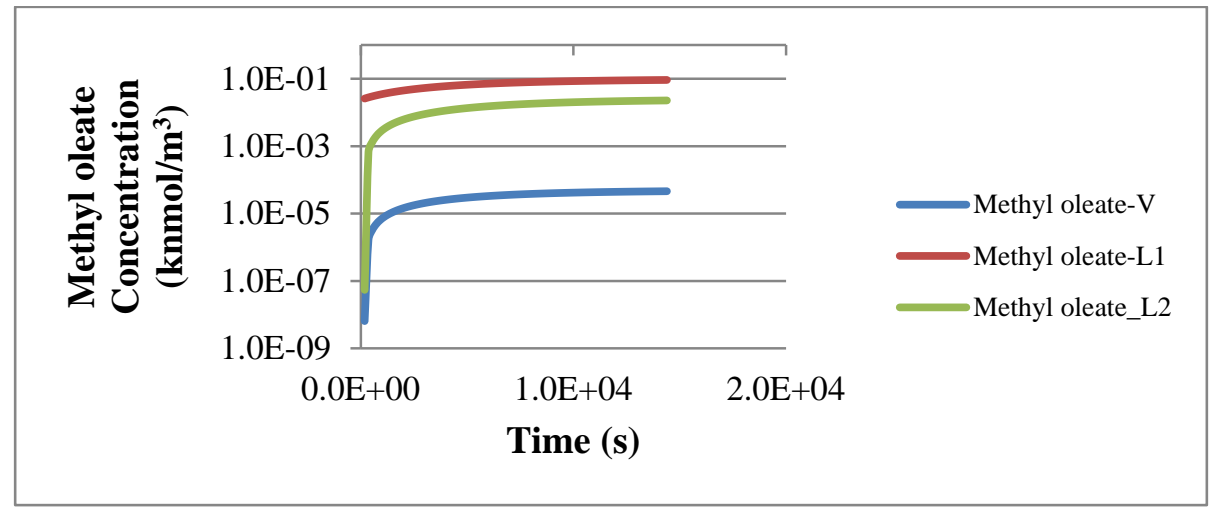

(c) Methyl-oleate concentration profiles

Figure 19. Concentrations with time (see color e-copy to distinguish curves)

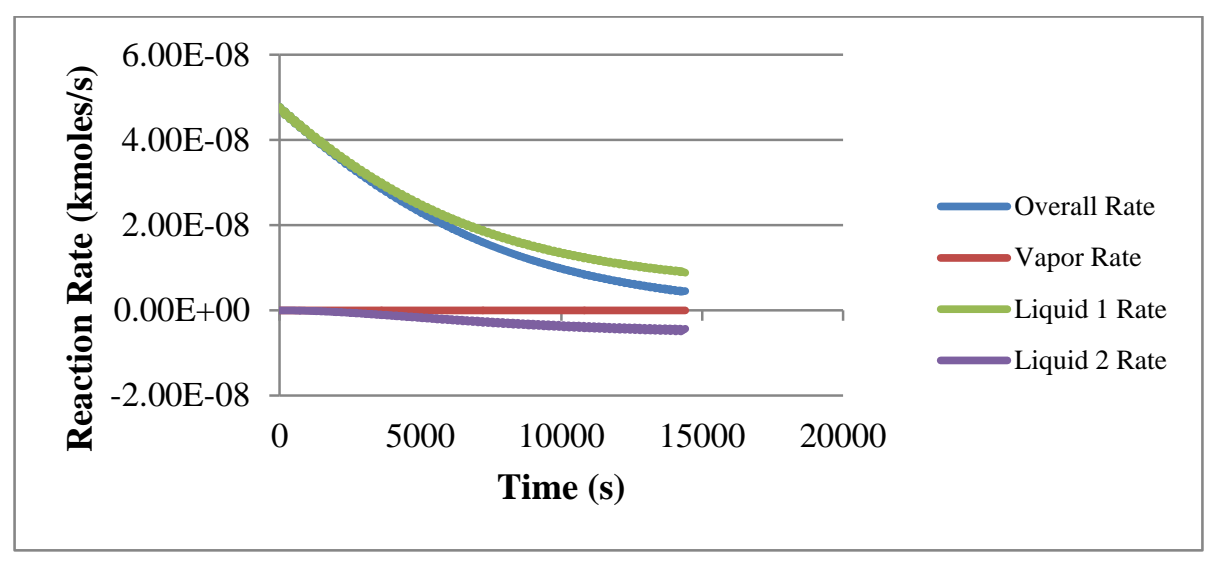

Figure 20. Reaction rates (see color e-copy to distinguish curves) 
Although conversions are comparable when using the same kinetic constants, the reaction proceeds slower in this 3-phase model than in the 1-phase model in MS Excel, with 77.3\% of triolein converted compared to 81.6\%), which does not agree with the experimental data [5]. This is likely because RK-ASPEN under-predicts the solubility of methanol in the triolein phase. The high solubility also explains why the Gibbs flash method predicts only one liquid phase, because it has difficulty distinguishing between two phases with high mutual solubility. Clearly, more robust phase equilibria algorithms, which check the phase stability, are needed to analyze this system.

\section{Conclusions}

Biodiesel production, using supercritical fluids, has gained interest in the last several years [5-7]. Numerous attempts have been made to model this system, but almost all previous studies used cubic equations-of-state [3, 4, 8-15]. It should be noted herein that the cubic plus EoS is more advanced than RK-ASPEN, and in future studies it would be instructive to compare the SAFT equations to this EoS [9-15]. Another study has also examined several binary systems (including $\mathrm{CO}_{2}$ and water, and $\mathrm{CO}_{2}$ and FAME) using the soft-SAFT EoS [16]. This work, however, was the first to examine a complete biodiesel system with two versions of SAFT. Herein, PC-SAFT in ASPEN PLUS and SAFT- $\gamma$ Mie (gSAFT) in gPROMS were compared to RK-ASPEN in ASPEN PLUS for pure-species, binary, and ternary systems.

A simplified biodiesel system using six species (triolein, methanol, carbon dioxide, methyl-oleate, glycerol, and water) has been studied. For the pure species, all three equations matched the liquid vapor-pressure data, but only the SAFT EoSs correctly predicted the liquid densities. PC-SAFT's VLE predictions were poorer on average than those of gSAFT and RKASPEN, but it provided the best agreement with LLE data. PC-SAFT gave good predictions for the ternary LLE systems, and for portions of the triolein, methanol, carbon dioxide mixture phase map, but ultimately none of the EoSs studied herein gave accurate predictions for the triolein, methanol, and $\mathrm{CO}_{2}$ mixtures. For PC-SAFT, this shortcoming was attributed to phase instability. Whereas, for gSAFT, the poor predictions in the VLLE region are likely to be a combination of improper weighting factors in regression of parameters from experimental data and the lower accuracy of using a group-contribution methodology. However, the SAFT EoSs are clearly more robust than RK-ASPEN, and given Figure 16(d) and the unstable phase distributions in the two 
polygons in Figure 17, it is likely that PC-SAFT can correctly representing the phase distribution for this system. In future work, a single-group molecule approach should be used in gSAFT to determine the full extent of its predictive capabilities, as it incorporates a more robust phase equilibria algorithm than ASPEN PLUS; that is, gSAFT checks the phase stability after convergence of flash calculations.

RK-ASPEN (with no binary parameters) gave reasonable agreement with experimental results in the VLLE region, and thus, was used in the thermo-kinetic reactor model. The model showed comparable conversions in the VLLE and supercritical regions. This is economically promising, suggesting that the much lower pressure VLLE systems can achieve high conversions. As newer flash algorithms are introduced in ASPEN PLUS and the parameter databank in gSAFT becomes more refined, it will become possible to model these reactions and the accompanying separations with greater accuracy, eventually allowing an extractiontransesterification process to be synthesized, optimized, and economically evaluated.

\section{Nomenclature}

\section{Variables and}

Parameters

$[C]$

[cat]

[glycerol]

[methanol]

[methyl-oleate]

[TG $\left.G_{\text {branch }}\right]$

$a$

A

$b$

$C$

$d$

D

$e$

F

\section{Meaning}

Concentration

Catalyst concentration

Concentration of glycerol

Concentration of methnaol

Concentration of methyl-oleate

Concentration of $T G_{\text {branch }}$

EoS parameter

Helmholtz free energy

EoS parameter

EoS parameter

EoS parameter

Collision diameter

EoS parameter

Tangent-plane-distance function

\section{Units}

$\mathrm{kmol} / \mathrm{m}^{3}$

$\mathrm{kmol} / \mathrm{m}^{3}$

$\mathrm{kmol} / \mathrm{m}^{3}$

$\mathrm{kmol} / \mathrm{m}^{3}$

$\mathrm{kmol} / \mathrm{m}^{3}$

$\mathrm{kmol} / \mathrm{m}^{3}$

$\mathrm{J}$

m

$\mathrm{J}$ 


\begin{tabular}{|c|c|c|}
\hline$f$ & Fugacity & $\mathrm{Pa}$ \\
\hline G & Gibbs free energy & $\mathrm{J}$ \\
\hline K & Binary interaction parameter & - \\
\hline$k$ & Rate constant & $\left(\mathrm{m}^{3}\right)^{2} /\left(\mathrm{kmol}^{2}-\mathrm{s}\right)$ \\
\hline$k_{\mathrm{B}}$ & Boltzmann's constant & $\mathrm{J} /$ molecule-K \\
\hline$m$ & Segment length & - \\
\hline$M$ & $\begin{array}{l}\text { No. of association sites on each } \\
\text { molecule }\end{array}$ & - \\
\hline$N$ & Number of molecules & molecules \\
\hline$n$ & Exponent & - \\
\hline NC & Number of chemical species & - \\
\hline$N G$ & Number of groups & - \\
\hline$n g$ & Number of groups in a molecule & - \\
\hline$n s g$ & Number of sites on a group & - \\
\hline NST & Number of sites & - \\
\hline$P$ & Pressure & $\mathrm{Pa}$ \\
\hline$R$ & Universal gas constant & $\mathrm{J} / \mathrm{mol}-\mathrm{K}$ \\
\hline$r$ & Radial distance between segments & $\mathrm{m}$ \\
\hline$r x n$ & Intrinsic reaction rate & $\mathrm{kmol} / \mathrm{m}^{3}-\mathrm{s}$ \\
\hline$S$ & Empirical square-well parameter & $\mathrm{m}$ \\
\hline$s$ & Shape parameter & - \\
\hline$T$ & Temperature & K \\
\hline$t$ & Time & s \\
\hline$u$ & Square-well potential energy & $\mathrm{J}$ \\
\hline V & Volume & $\mathrm{m}^{3}$ \\
\hline W & Non-normalized mole fraction & - \\
\hline$x$ & Mole fraction & - \\
\hline$X$ & Association mole fraction & - \\
\hline$y$ & Mole fraction & - \\
\hline$Y$ & Moles & mol \\
\hline$z$ & Mole fraction & - \\
\hline
\end{tabular}


Z

Greek Symbols

$\alpha$

$\gamma$

$\Gamma$

$\varepsilon$

$\zeta$

$\eta$

$\kappa$

$\lambda$

$\mu$

$v$

$\rho$

$\sigma$

$\varphi$

$\Phi$

$\omega$

$\Omega$

$\underline{\text { Subscript }}$

1

2

a

A

at

b

B

C

f

m
Moles

\section{Meaning}

Temperature fitting parameter

Accentricity fitting parameter

Objective function

Energy of the square-well interaction

Reduced density

Extra polar parameter

Association bonding volume

Range of the interaction

Chemical potential

Stochiometric coefficient

Number density

Segment diameter

Fugacity coefficient

Objective function

Accentric factor

Minimum interaction parameter mol

\section{$\underline{\text { Units }}$}

$\mathrm{J}$

$\mathrm{m}^{3}$

$\mathrm{m}$

$\mathrm{J} / \mathrm{mol}$

Molecules $/ \mathrm{m}^{3}$

$\mathrm{m}$

\section{Meaning}

Order of perturbation term

Order of perturbation term

Relating to parameter a

Association

Attractive

Relating to parameter b

Association

Critical

Forward

Mixing 


$\begin{array}{cl}\mathrm{n} & \text { Power of the collision diameter } \\ \mathrm{r} & \text { Reduced } \\ \mathrm{R} & \text { Repulsive } \\ \mathrm{R} 1 & \text { Relating to reaction } \mathrm{R} 1 \\ \mathrm{ref} & \text { Reference } \\ \mathrm{rev} & \text { Reverse }\end{array}$

\section{Superscript}

0

1

A

assoc

B

chain

disp

HB

hc

ig

mono

polar

$\mathrm{T}$

\section{Meaning}

Binary interaction coefficient order

Binary interaction coefficient order

Associating group

Association contribution

Associating group

Chain contribution

Dispersion contribution

Associating

Hard-chain contribution

Ideal-gas contribution

Monomer contribution

Polar contribution

Tangent

\section{Acknowledgments}

Partial financial support from the U.S. Department of Energy for the project, Algal Biofuels (Contract /DE-EE0003046), awarded to the National Alliance for Biofuels and Bioproducts (NAABB), is acknowledged gratefully. The papers and advice provided by Prof. Esteban Brignole in the early stages of this work are very much appreciated. Close interactions with Prof. Kimberly Ogden and NAABB researchers at the University of Arizona, especially in arranging for the collaboration of the Penn, Yale, and Lafayette co-authors, are appreciated. 


\section{Appendix A. Experimental Data}

The data measured according to the methods described in Section 3 are listed in Tables A.1-A.5. Table A.1 provides the only vapor-liquid equilibrium dataset. All others provide liquid-liquid equilibria. For the LLE datasets, each temperature was measured twice; however, some experiments resulted in physically impossible concentrations. A dash is used to denote this in the tables. Finally, for the methanol and triolein (Table A.2) and water and triolein (Table A.5) LLE datasets, only one of the liquid phases could be sampled. The data in all tables is accurate to three significant figures.

Table A.1. Methanol and Methyl-oleate VLE (mole fractions)

\begin{tabular}{|c|c|c|c|c|}
\hline $\mathrm{T}(\mathrm{K})$ & $x$, Methanol & $\begin{array}{c}x, \\
\text { Methyl-oleate }\end{array}$ & $y$, Methanol & $\begin{array}{c}y, \\
\text { Methyl-oleate }\end{array}$ \\
\hline 342.25 & 0.672 & 0.328 & 1.000 & 0.000291 \\
\hline 346.95 & 0.484 & 0.516 & 1.000 & 0.000271 \\
\hline 356.75 & 0.346 & 0.654 & 0.999 & 0.00141 \\
\hline 362.65 & 0.239 & 0.761 & 0.999 & 0.000840 \\
\hline 372.85 & 0.145 & 0.855 & 0.999 & 0.000955 \\
\hline 384.15 & 0.104 & 0.896 & 0.998 & 0.00153 \\
\hline 394.65 & 0.0759 & 0.924 & 0.998 & 0.00218 \\
\hline 414.85 & 0.0528 & 0.947 & 0.997 & 0.00284 \\
\hline 435.15 & 0.0552 & 0.945 & 0.996 & 0.00362 \\
\hline
\end{tabular}

Table A.2. Methanol and Triolein LLE (mole fractions)

\begin{tabular}{|c|c|c|}
\hline $\mathrm{T}(\mathrm{K})$ & $x_{1}$, Methanol & $x_{1}$, Triolein \\
\hline 303.15 & 1.000 & 0.0000758 \\
\hline 303.15 & 1.000 & 0.0000877 \\
\hline 303.15 & 1.000 & 0.0000879 \\
\hline 308.15 & 1.000 & 0.000110 \\
\hline 308.15 & 1.000 & 0.000147 \\
\hline 308.15 & 1.000 & 0.000148 \\
\hline 313.15 & 1.000 & 0.000082 \\
\hline 313.15 & 1.000 & 0.000128 \\
\hline 318.15 & 1.000 & 0.000118 \\
\hline 318.15 & 1.000 & 0.000120 \\
\hline 318.15 & 1.000 & 0.000140 \\
\hline 313.15 & 1.000 & 0.000305 \\
\hline
\end{tabular}




\begin{tabular}{|l|l|l|}
328.15 & 1.000 & 0.000168 \\
\hline 328.15 & 1.000 & 0.000259 \\
\hline 333.15 & 1.000 & 0.000173 \\
\hline 333.15 & 1.000 & 0.000207 \\
\hline
\end{tabular}

Table A.3. Glycerol and Methyl-oleate LLE (mole fractions)

\begin{tabular}{|c|c|c|c|c|}
\hline Temperature $(\mathrm{K})$ & $x_{1}$, Glycerol & $x_{1}$, Methyl-oleate & $x_{2}$, Glycerol & $x_{2}$, Methyl-oleate \\
\hline 323.15 & 0.00231 & 0.998 & - & - \\
\hline 323.15 & 0.00389 & 0.996 & 0.989 & 0.0111 \\
\hline 333.15 & 0.00317 & 0.997 & 0.992 & 0.00811 \\
\hline 333.15 & 0.00309 & 0.997 & 0.997 & 0.00318 \\
\hline 343.15 & 0.00513 & 0.995 & 0.999 & 0.00140 \\
\hline 343.15 & 0.00419 & 0.996 & 0.999 & 0.00122 \\
\hline 353.15 & 0.00510 & 0.995 & 0.996 & 0.00376 \\
\hline 353.15 & 0.00542 & 0.995 & 0.992 & 0.00792 \\
\hline 363.15 & 0.00627 & 0.994 & 0.998 & 0.00207 \\
\hline 363.15 & 0.00690 & 0.993 & 0.984 & 0.0161 \\
\hline 373.15 & 0.00993 & 0.990 & 0.995 & 0.00470 \\
\hline 373.15 & 0.00906 & 0.991 & 0.956 & 0.0445 \\
\hline 383.15 & 0.0121 & 0.988 & 1.000 & 0.000208 \\
\hline 383.15 & 0.0128 & 0.987 & 0.997 & 0.00272 \\
\hline
\end{tabular}

Table A.4. Glycerol and Triolein LLE (mole fractions)

\begin{tabular}{|c|c|c|c|c|}
\hline Temperature $(\mathrm{K})$ & $x_{1}$, Triolein & $x_{1}$, Glycerol & $x_{2}$, Triolein & $x_{2}$, Glycerol \\
\hline 323.15 & 0.000371 & 1.000 & - & - \\
\hline 323.15 & 0.000421 & 1.000 & 0.997 & 0.00306 \\
\hline 333.15 & 0.0252 & 0.975 & 0.995 & 0.00499 \\
\hline 333.15 & - & - & 0.995 & 0.00453 \\
\hline 343.15 & 0.00255 & 0.997 & 0.993 & 0.00716 \\
\hline 343.15 & 0.0134 & 0.987 & 0.994 & 0.00559 \\
\hline 353.15 & 0.00459 & 0.995 & 0.993 & 0.00713 \\
\hline 353.15 & - & - & 0.994 & 0.00562 \\
\hline 363.15 & 0.00224 & 0.998 & 0.993 & 0.00719 \\
\hline 363.15 & - & - & 0.993 & 0.00688 \\
\hline 383.15 & 0.000820 & 0.999 & 0.981 & 0.0191 \\
\hline 383.15 & 0.000767 & 0.999 & 0.975 & 0.0254 \\
\hline
\end{tabular}


Table A.5. Water and Triolein LLE (mole fractions)

\begin{tabular}{|c|c|c|}
\hline Temperature $(\mathrm{K})$ & $x_{1}$, Triolein & $x_{1}$, Water \\
\hline 323.15 & $1.87 \mathrm{E}-04$ & 1.000 \\
\hline 333.15 & $3.96 \mathrm{E}-05$ & 1.000 \\
\hline 333.15 & $8.99 \mathrm{E}-06$ & 1.000 \\
\hline 333.15 & $2.33 \mathrm{E}-04$ & 1.000 \\
\hline 341.15 & $1.83 \mathrm{E}-05$ & 1.000 \\
\hline 341.15 & $6.17 \mathrm{E}-06$ & 1.000 \\
\hline 341.15 & $1.10 \mathrm{E}-05$ & 1.000 \\
\hline 348.15 & $2.00 \mathrm{E}-05$ & 1.000 \\
\hline 348.15 & $5.78 \mathrm{E}-05$ & 1.000 \\
\hline 348.15 & $3.48 \mathrm{E}-06$ & 1.000 \\
\hline 355.15 & $1.85 \mathrm{E}-05$ & 1.000 \\
\hline 355.15 & $7.50 \mathrm{E}-06$ & 1.000 \\
\hline 355.15 & $2.01 \mathrm{E}-05$ & 1.000 \\
\hline 363.15 & $1.76 \mathrm{E}-05$ & 1.000 \\
\hline 363.15 & $7.00 \mathrm{E}-06$ & 1.000 \\
\hline
\end{tabular}

\section{References}

1. Silva, C.S., Soliman, E., Cameron, G., Fabiano, L.A., Seider, W.D., Dunlop, E.H., Coaldrake, A.K., 2014. Commercial-Scale Biodiesel Production from Algae. Ind. Eng. Chem. Res. 53, p. 5311-5324.

2. Soh, L., Zimmerman, J., 2011. Biodiesel Production: The Potential of Algal Lipids Extracted with Supercritical Carbon Dioxide. Green Chem. 13, p. 1422-1429.

3. Glisic, S.B., Orlovic, A.M., 2014. Review of Biodiesel Synthesis from Waste Oil under Elevated Pressure and Temperature: Phase Equilibrium, Reaction Kinetics, Process Design, and Techno-Economic Study. Renew. Sustain. Energy Revs. 31, p. 708-725.

4. Macaira, J., Santana, A., Costa, A., Ramirez, E., Larroyoz, M.A., 2014. Process Intensification Using Co2 as a Cosolvents under Supercritical Conditions Applied to Design of Biodiesel Production. Ind. Eng. Chem. Res. 53, p. 3985-3995.

5. Soh, L., Curry, J., Beckman, E.J., Zimmerman, J.B., 2013. Effect of System Conditions for Biodiesel Production Via Transesterification Using Carbon Dioxide-Methanol Mixtures in the Presence of a Heterogeneous Catalyst. ACS Sustain. Chem. Eng. 2, p. 387-395.

6. Changi, S., Pinnarat, T., Savage, P.E., 2011. Mechanistic Modeling of Hydrolysis and Esterification for Biofuel Processes. Ind. Eng. Chem. Res. 50, p. 12471-12478. 
7. Patil, P.D., Grude, V.D., A. Mannarswamy, Deng, S., Cooke, P., Munson-McGee, S., Rhodes, I., Lammers, P., Nirmalakandan, N., 2011. Optimization of Direct Conversion of Wet Algae-to-Biodiesel under Supercritical Methanol Conditions. Bioresour. Technol. 102, p. 118-122.

8. Anikeev, V., Stepanov, D., Yermakova, A., 2012. Thermodynamics of Phase and Chemical Equilibrium in the Processes of Biodiesel Fuel Synthesis in Subcritical and Supercritical Methanol. Ind. Eng. Chem. Res. 51, p. 4783-4796.

9. $\quad$ Andreatta, A.E., Casas, L.M., Hegel, P., Bottini, S.B., Brignole, E.A., 2008. Phase Equilibria in Ternary Mixtures of Methyl Oleate, Glycerol, and Methanol. Ind. Eng. Chem. Res. 47, p. 5157-5164.

10. Andreatta, A.E., Lugo, R., Hemptinne, J.C.d., Brignole, E.A., Bottini, S.B., 2010. Phase Equilibria Modeling of Biodiesel Related Mixtures Using the Gca-Eos Model. Fluid Phase Equil. 296.

11. Oliveira, M.B., Queimada, A.J., Coutinho, J.A.P., 2010. Prediction of near and Supercritical Fatty Acid Ester + Alcohol Systems with the Cpa Eos. Journal of Supercritical Fluids 52, p. 241-248.

12. Oliveira, M.B., Queimada, A.J., Kontogeorgis, G.M., Coutinho, J.A.P., 2011. Evaluation of the Co2 Behavior in Binary Mixtures with Alkanes; Alcohols; Acids and Esters Using the Cubic-PlusAssociation Equation of State. Journal of Supercritical Fluids 55, p. 876-892.

13. Oliveira, M.B., Varanda, F.R., Marrucho, I.M., Queimada, A.J., Coutinho, J.A.P., 2008.

Prediction of Water Solubility in Biodiesel with the Cpa Equation of State. Ind. Eng. Chem. Res. 47, p. 4278-4285.

14. Regueira, T., Carvalho, P.J., Oliveira, M.B., Lugo, L., Coutinho, J.A.P., Fernández, J., 2013.

Experimental Measurements and Modelling of Co2 Solubility in Sunflower, Castor and Rapeseed Oils. The Journal of Supercritical Fluids 82, p. 191-199.

15. Velez, A., Hegel, P., Mabe, G., Brignole, E.A., 2010. Density and Conversion in Biodiesel Production with Supercritical Methanol. Ind. Eng. Chem. Res. 49, p. 7666-7670.

16. Llovell, F., Vega, L.F., 2015. Accurate Modeling of Supercritical Co2 for Sustainable Processes: Water + Co2 and Co2 + Fatty Acid Esters Mixtures. Journal of Supercritical Fluids 96, p. 86-95.

17. Hegel, P., Mabe, G., Pereda, S., Brignole, E.A., 2007. Phase Transitions in a Biodiesel Reactor Using Supercritical Methanol. Ind. Eng. Chem. Res. 46, p. 6360-6365.

18. Gross, J., Sadowski, G., 2001. Perturbed-Chain Saft: An Equation of State Based on a Perturbation Theory for Chain Molecules. Ind. Eng. Chem. Res. 40, p. 1244-1260.

19. Gross, J., Sadowski, G., 2002. Application of the Perturbed-Chain Saft Equation of State to Associating Systems. Ind. Eng. Chem. Res. 41, p. 5510-5515.

20. Lymperiadis, A., Adjiman, C.S., Galindo, A., Jackson, G., 2007. A Group Contribution Method for Associating Chain Molecules Based on the Statistical Associating Fluid Theory (Saft- $\Gamma$ ). J. Chem. Phys. 127, p. 234903-234901 - 234903-234922. 
21. Papaioannou, V., Lafitte, T., Avendaño, C., Adjiman, C.S., Jackson, G., Müller, E.A., Galindo, A., 2014. Group Contribution Methodology Based on the Statistical Associating Fluid Theory for Heteronuclear Molecules Formed from Mie Segments. J Chem. Phys. 140, p. 054107.

22. Soave, G., 1972. Equilibrium Constants from a Modified Redlich-Kwong Equation of State. Chemical Engineering Science 27, p. 1197-1203.

23. Peng, D.Y., Robinson, D.B., 1976. A New Two-Constant Equation of State. Ind. Eng. Chem. Fund. 15, p. 59-64.

24. Aspentech. Aspen Physical Property System. Burlington, Ma: Aspen Technology, Nov. 2013. Pdf.

25. Chapman, W.G., Gubbins, K.E., Jackson, G., Radosz, M., 1990. New Reference Equation of State for Associating Liquids. Ind. Eng. Chem. Res. 29, p. 1709-1721.

26. Wertheim, M.S., 1984. Fluids with Highly Directional Attractive Forces: Ii. Thermodynamic Perturbation Theory and Integral Equations. J. Stat. Phys. 35, p. 35-47.

27. Wertheim, M.S., 1986. Fluids with Highly Directional Attractive Forces: Iii. Multiple Attraction Sites. J. Stat. Phys. 42, p. 459-476.

28. Wertheim, M.S., 1986. Fluids with Highly Directional Attractive Forces: Iv. Equilibrium Polymerization. J. Stat. Phys. 42, p. 477-492.

29. Wertheim, M.S., 1984. Fluids with Highly Directional Attractive Forces: I. Statistical Thermodynamics. J. Stat. Phys. 35, p. 19.

30. Ominik, A., Chapman, W.G., Kleiner, M., Sadowski, G., 2005. Modeling of Polar Systems with the Perturbed-Chain Saft Equation of State. Investigation of the Performance of Two Polar Terms. Ind. Eng. Chem. Res. 44, p. 6928-6938.

31. Poling, B.E., Prausnitz, J.M., O’Connell, J.P., 2001. The Properties of Gases and Liquids, 5 ed. McGraw-Hill, New York, NY. Chapter 2: Pure Component Constants.

32. Fredenslund, A., Jones, R.L., Prausnitz, J.M., 1975. Group-Contribution Estimation of Activity Coefficients in Nonideal Liquid Mixtures. AIChE J. 21, p. 1086-1099.

33. Espinosa, S., Fornari, T., Bottini, S.B., Brignole, E.A., 2002. Phase Equilibria in Mixtures of Fatty Oils and Derivatives with near Critical Fluids Using the Gc-Eos Model. J. Supercrit. Fluids 23, p. 91-102.

34. Paricaud, P., 2006. A General Perturbation Approach for Equation of State Development: Applications to Simple Fluids, Ab Initio Potentials, and Fullerenes. J. Chem. Phys. 124, p. 154505154501 - 154505-154517.

35. Gautam, R., Seider, W.D., 1979. Calculation of Phase and Chemical Equilibria, Parts I-III. AIChE J. 25, p. 991-1015. 
36. Iglesias-Silva, G.A., Bonilla-Petriciolet, A., Eubank, P.T., Holste, J.C., Hall, K.R., 2003. An Algebraic Method That Includes Gibbs Minimization for Performing Phase Equilibrium Calculations for Any Number of Components or Phases. Fluid Phase Equil. 210, p. 229-245.

37. Ne'ron, A., Lantagne, G., Marcos, B., 2012. Computation of Complex and Constrained Equilibria by Minimization of the Gibbs Free Energy. Chem. Eng. Sci. 82, p. 260-271.

38. White, C.W., III, Seider, W.D., 1981. Computation of Phase and Chemical Equilibrium. AIChE J. 27, p. 466-471.

39. McDonald, C.M., Floudas, C.A., 1995. Global Optimization for the Phase and Chemical Equilibrium Problem: Application to the Nrtl Equation. Comput. Chem.Eng. 19, p. 1111-1141.

40. Nichita, D.V., Gomez, S., Luna, E., 2002. Multiphase Equilibria Calculation by Direct Minimization of Gibbs Free Energy with a Global Optimization Method. Computers and Chem. Eng. 26, p. $1703-1724$.

41. McDonald, C.M., Floudas, C.A., 1995. Global Optimization for the Phase Stability Problem. AIChE J. 41, p. 1798-1814.

42. Michelsen, M.L., Mollerup, J., 2007. Thermodynamic Models: Fundamentals and Computational Aspects. 2 ed; Tie-Line Publications.

43. Sun, A.C., Seider, W.D., 1995. Homotopy-Continuation Method for Stability Analysis in the Global Minimization of the Gibbs Free Energy. Fluid Phase Equil. 103, p. 213-249.

44. Prof. Romain Privat's Homepage, $<$ http://lrgp.univ-lorraine.fr/axes-de-recherche/reactions-etreacteurs/thermodynamique-et-energietherme/permanents/fiche/?tx_wecstaffdirectory_pi1\%5Bcurstaff\%5D=130>, [Accessed 05/06/2015]. 45. ASTM, 2013. Standard Test Method for Determination of Total Monoglycerides, Total Diglycerides, Total Triglycerides, and Free and Total Glycerin in B-100 Biodiesel Methyl Esters by Gas Chromatography, West Conshohocken, PA, 2013.

46. Britt, H.I., Luecke, R.H., 1973. The Estimation of Parameters in Nonlinear, Implicit Models. Technometrics 15, p. 233-247.

47. Marquardt, D.W., 1963. An Algorithm for Least-Squares Estimation of Nonlinear Parameters. $J$. Soc. Indust. Appl. Math. 11, p. 431-441.

48. Nist Data Bank. Aspen Plus.

49. Bonhorst, C.W., Althouse, P.M., Triebold, H.O., 1948. Esters of Naturally Occurring Fatty Acids-Physical Properties of Methyl, Propyl, and Isopropyl Esters of C6 to C18 Saturated Fatty Acids. Industrial \& Engineering Chemistry 40, p. 2379-2384. 
50. Ott, L.S., Huber, M.L., Bruno, T.J., 2008. Density and Speed of Sound Measurements on Five Fatty Acid Methyl Esters at 83 Kpa and Temperatures from (278.15 to 338.15) K. J. Chem. Eng. Data 53, p. 2412-2416.

51. Pratas, M.J., Freitas, S., Oliveira, M.B., Monteiro, S.C., Lima, A.S., Coutinho, J.A.P., 2010. Densities and Viscosities of Fatty Acid Methyl and Ethyl Esters. J. Chem. Eng. Data 55, p. 3983-3990.

52. Yuan, W., Hansen, A.C., Zhang, Q., 2005. Vapor Pressure and Normal Boiling Point Predictions for Pure Methyl Esters and Biodiesel Fuels. Fuel 84, p. 943-950.

53. Association, G.P., 1963. Physical Properties of Glycerine and Its Solutions, New York.

54. Cammenga, H.K., Schulze, F.W., Theuerl, W., 1977. Vapor Pressure and Evaporation Coefficient of Glycerol. J. Chem. Eng. Data 22, p. 131-134.

55. Duschek, W., Kleinrahm, R., Wagner, W., 1990. Measurement and Correlation of the (Pressure, Density, Temperature) Relation of Carbon Dioxide I. The Homogeneous Gas and Liquid Regions in the Temperature Range from $217 \mathrm{~K}$ to $340 \mathrm{~K}$ at Pressures up to 9 Mpa. J. Chem. Thermo. 22, p. 827-840.

56. Perry, E.S., Weber, W.H., Daubert, B.F., 1949. Vapor Pressures of Phlegmatic Liquids. I. Simple and Mixed Triglycerides. J. Am. Chem. Soc. 71, p. 3720-3726.

57. Santander, C.M.G., Rueda, S.M.G., Silva, N.d.L.d., Camargo, C.L.d., Kieckbusch, T.G., Maciel, M.R.W., 2011. Measurements of Normal Boiling Points of Fatty Acid Ethyl Esters and Triacylglycerols by Thermogravimetric Analysis. Fuel 92, p. 158-161.

58. Perry, R.H., Green, D.W., 2007. Perry's Handbook of Chemical Engineering. Vol. 8 McGrawHill Professional.

59. Saleh, B., Wendland, M., 2005. Measurement of Vapor Pressures and Saturated Liquid Densities of Pure Fluids with a New Apparatus. J. Chem Eng. Data 50, p. 429-437.

60. Stull, D.R., 1947. Vapor Pressure of Pure Substances. Organic and Inorganic Compounds. Ind. Eng. Chem. Res. 39, p. 517-540.

61. Carbon Dioxide Thermophysical Properties <http://webbook.nist.gov/cgi/cbook.cgi?ID=C124389\&Mask=4>, [Accessed 04/30/2014].

62. Koohyar, F., Rostami, A.A., Chaichi, M.J., Kiani, F., 2013. Study on Thermodynamic Properties for Binary Systems of Water + L-Cysteine Hydrochloride Monohydrate, Glycerol, and D-Sorbitol at Various Temperatures. J.Chem. 2013, p. 1-10.

63. Korgitzsch, F.M., 1993. Study of Phase Equilibria as a Fundament for the Refinement of Vegetable and Animal Fats and Oils. Technical University of Berlin.

64. Soujanya, J., Satyavathi, B., Prasad, T.E.V., 2010. Experimental (Vapour+ Liquid) Equilibrium Data of (Methanol+Water), (Water+Glycerol) and (Methanol+Glycerol) Systems at Atmospheric and Sub-Atmospheric Pressures. J. Chemi. Thermo. 42, p. 621-624. 
65. Ye, K., Freund, H., Xie, Z., Subramaniam, B., Sundmacher, K., 2012. Prediction of Multicomponent Phase Behavior of Co2-Expanded Liquids Using Ceos Models and Comparison with Experimental Data. J. Supercrit. Fluids 67, p. 41-52.

66. Tang, Z., Du, Z., Min, E., Gao, L., Jiang, T., Han, B., 2006. Phase Equilibria of Methanol-Triolein System at Elevated Temperature and Pressure. Fluid Phase Equil. 239, p. 8-11.

67. Lee, M.J., Lo, Y.C., Lin, H.M., 2010. Liquid-Liquid Equilibria for Mixtures Containing Water, Methanol, Fatty Acid Methyl Esters, and Glycerol. Fluid Phase Equil. 299, p. 180-190.

68. Soh, L., Chen, C.C., Kwan, T.A., Zimmerman, J.B., 2015. Role of Co2 in Mass Transfer, Reaction Kinetics, and Inter-Phase Partitioning for the Transesterification of Triolein in an Expanded Methanol System with Heterogeneous Acid Catalyst. Submitted to Sustainable Chemistry and Engineering. 